\title{
Chinese herbal medicines as a source of molecules with anti-enterovirus 71 activity
}

Mengjie Wang ${ }^{1,2}$, Ling Tao ${ }^{1,2,3}$ and Hongxi $\mathrm{Xu}^{1,2^{*}}$

\begin{abstract}
Enterovirus 71 (EV71) is one of the causative agents of hand, foot, and mouth disease (HFMD), which sometimes leads to severe neurological disease and death in the Asia-Pacific region. In Chinese medicine, HFMD is caused mainly by an accumulation of damp-heat and toxicity in the body. No effective drugs are currently available for the treatment and prevention of EV71 infection. This review summarizes the potential Chinese herbal extracts and isolated compounds with antiviral activity against EV71 and their clinical applications, especially those categorized as heat-clearing and detoxifying.
\end{abstract}

\section{Background}

Enterovirus 71 (EV71) is a non-enveloped, positive-sense, single-stranded RNA virus that is $7.4 \mathrm{~kb}$ in length and belongs to the family Picornaviridae [1]. Infection with EV71 commonly causes mild hand, foot, and mouth disease (HFMD), which sometimes leads to serious neurological complications such as aseptic meningitis, brain stem encephalitis, pulmonary edema, and poliomyelitislike paralysis, and eventually causes death especially in infants and children [2]. The potential fatal implications pose a great threat to infants and children under 5 years of age [3]. Since the first isolation of EV71 in the United States in 1969, there have been several outbreaks of EV71 in Bulgaria, Malaysia, Taiwan, and China that caused considerable levels of infection and mortality [4-7]. However, neither a precautionary vaccine nor a specific antiviral drug is available for the treatment of EV71 infection [6].

Interferons (IFNs) are a group of antiviral proteins (mainly glycoproteins) that regulate host cytokines and chemokines [8]. Infection with EV71 attenuates the IFN response, and reduces the antiviral effect of IFNs [9]. Although ribavirin, a nucleoside analog, has been clinically used as a broad-spectrum antiviral drug, treatment of EV71 infection by ribavirin has been unsatisfactory

\footnotetext{
*Correspondence: xuhongxi88@gmail.com

${ }^{1}$ School of Pharmacy, Shanghai University of Traditional Chinese

Medicine, Shanghai 201203, China

Full list of author information is available at the end of the article
}

with considerable side effects in infants and children $[10,11]$. Pleconaril, an antipicornavirus capsid-binding agent, shows moderate efficacy in anti-EV71 treatment, but cannot reduce the cytopathic effect (CPE) induced by some EV71 strains $[12,13]$. Rupintrivir, an inhibitor of human rhinovirus (HRV) 3C protease, specifically binds to the $3 \mathrm{C}$ protease of EV71, inhibits the replication of EV71 in vitro, and strongly contains the spread of EV71 infection in vivo [14]. However, this drug has not yet been used for clinical treatment of EV71 infection.

In addition to synthetic compound design, Chinese herbal medicines (CHMs) contain a wide range of phytochemicals and comprise a potential source of anti-EV71 active agents [15]. According to Chinese medicine (CM) theory, diseases occur and develop through the effects of pathogenic factors on the human body that lead to an imbalance of qi, xue, yin, and yang, or organs and meridians in the body [16]. Herbs have different impacts on the human body to regulate qi, xue, yin, and yang, and balance the whole body. HFMD is caused mainly by an accumulation of damp-heat and toxicity in the body, and therefore its treatment may involve the usage of heatclearing and detoxifying medicines. In this review, studies on CHM extracts and compounds with anti-EV71 activity are summarized, based on CHMs categorized into heat-clearing and detoxifying medicines. Future perspectives and challenges in anti-EV71 drug development involving herbal medicines are also discussed. 


\section{Extracts with anti-EV71 activity}

Extracts of CHMs have shown significant antiviral effects against EV71 with low $\mathrm{EC}_{50}$ values and high selective index (SI) values. Previous studies, formulae, and clinical experiences with CHMs and ethnomedicines revealed inhibitory effects on a range of viruses, such as influenza virus, hepatitis $B$ virus (HBV), dengue virus, and coxsackie virus B3 (CVB3) [17-20]. Extracts of CHMs may be complementary to modern medicines. Extracts with anti-EV71 activity are summarized in Table 1.

\section{Heat-clearing and detoxifying medicines}

Heat-clearing and detoxifying medicines comprise a variety of herbal medicines that can be used to treat heatrelated syndromes such as high body temperature, thirst in the mouth and throat, constipation, inflammation, and pain [21].

Houttuynia cordata Thunb. (Yu Xing Cao) eliminated heat and toxicity in the human body and promoted urination [22]. The herb exhibited anti-inflammatory, anticancer, and antiobesity activities, and blocked infection of herpes simplex virus (HSV) [23-26]. In a screening of 22 CHMs, a water extract of $H$. cordata Thunb. inhibited the CPE and plaque formation induced by EV71 in Vero cells with an $\mathrm{EC}_{50}$ of $125.92 \mu \mathrm{g} / \mathrm{mL}$ [27]. The H. cordata Thunb. extract $(125 \mu \mathrm{g} / \mathrm{mL})$ lowered the $50 \%$ viral RNA yield, reduced viral protein $3 \mathrm{~A}$ expression, and inhibited EV71-induced apoptosis in comparison with the untreated group, and among five tested pure compounds extracted from $H$. cordata Thunb., chlorogenic acid showed a moderate anti-EV71 effect with an $\mathrm{IC}_{50}$ of $102.53 \mu \mathrm{g} / \mathrm{mL}$. The water extract of $H$. cordata Thunb. had anti-EV71 activity against the Fuyang and $\mathrm{BrCr}$ strains in Vero cells with $\mathrm{EC}_{50}$ values of 8.9 and $20.6 \mu \mathrm{g} /$ $\mathrm{mL}$, respectively [28]. Incubation of the extract before or during inoculation significantly suppressed EV71 infection and also inhibited the CPE of coxsackievirus A16 (CVA16), another causative agent of HFMD. Pre-treatment with the extract prevented EV71-induced IKB $\alpha$ degradation and downregulated interleukin (IL)- 6 gene expression.

Paris polyphylla Smith (Qi Ye Yi Zhi Hua) is used for the treatment of snake bites [29]. P. polyphylla Smith possessed anticancer activity, and saponins from the herb exhibited antifungal effects [30,31]. The $95 \%$ ethanol extract of $P$. polyphylla Smith showed antiviral activity against four strains of EV71 and CVB3 with $\mathrm{EC}_{50}$ values of $78.46-125.00 \mu \mathrm{g} / \mathrm{mL}$ [32]. The extract inhibited both viral replication and associated increases in IL-6 levels.

Kalanchoe gracilis (KGS) (Deng Long Cao) can be used to treat injuries, pain, inflammation, and fever because of its antioxidative, anti-inflammatory, analgesic, and anticancer activities [33-35]. The water extract of KGS leaves exerted antiviral effects against EV71 and CVA16 with $\mathrm{EC}_{50}$ values of 35.88 and $42.91 \mu \mathrm{g} / \mathrm{mL}$, respectively [36]. The extract inhibited virus-induced apoptosis, inactivated viral $2 \mathrm{~A}$ protease, and reduced the expression of IL-6 and RANTES. The extract also reduced the virus yield in the intestine of EV71-infected suckling mice. The ethyl acetate (EA) fraction of the extract showed greater antiviral activity than the n-butanol or aqueous fractions, exhibiting $\mathrm{EC}_{50}$ values of $4.21 \mu \mathrm{g} / \mathrm{mL}$ against EV71 and $9.08 \mu \mathrm{g} / \mathrm{mL}$ against CVA16 [37]. Eupafolin, a major component of the EA fraction, showed $\mathrm{EC}_{50}$ values of $1.39 \mu \mathrm{M}$ against EV71 and 5.24 $\mu \mathrm{M}$ against CVA16. Eupafolin attenuated the virus-induced upregulation of IL-6 and RANTES by inhibiting the virus-induced ERK1/2, AP-1, and STAT3 signals.

Saururus chinensis (Lour.) Baill (San Bai Cao) exhibited a variety of bioactivities for the treatment of edema, jaundice, cancer, and inflammatory diseases [38]. The water extract of $S$. chinensis showed significant antiviral activity against EV71 with an $\mathrm{EC}_{50}$ of $8.9 \mu \mathrm{g} / \mathrm{mL}$ by inhibiting the activation of the MEK1/ERK signaling pathway, and rutin was identified as the major component responsible for this activity [36].

The bark, leaves, and flowers of Paulownia tomentosa (Pao Tong) have been applied to the treatment of infections and inflammatory diseases in CM [39]. The methanol extract of $P$. tomentosa flowers demonstrated anti-EV71 activity with a dose-dependent reduction of the CPE and an $\mathrm{EC}_{50}$ of $65 \mu \mathrm{g} / \mathrm{mL}$. Further bioactivity-guided isolation led to the discovery of the pure anti-EV71 compound apigenin, which inhibited viral replication [40].

The EA and butanol extract of Phyllanthus urinaria (Zhen $\mathrm{Zhu} \mathrm{Cao}$ ) was reported to possess antiviral activity against EV71 and CVA16 based on CPE reduction assays, with corilagin identified as the major active component [41].

\section{Other medicines}

Salvia miltiorrhiza (Dan Shen) has been widely used in CM to improve blood circulation, relieve blood stasis, and treat coronary heart disease [42]. Wu et al. [43] obtained seven extracts of S. miltiorrhiza, and two fractions derived from water extracts showed anti-EV71 activity in $\mathrm{CPE}$ inhibition assays with $\mathrm{EC}_{50}$ values of $0.742 \mathrm{mg} / \mathrm{mL}$ for fraction SA1 and $0.585 \mathrm{mg} / \mathrm{mL}$ for SA2. Both fractions exhibited antiviral activity against three strains of EV71 in Vero, RD, and MRC-5 cell lines. The extracts also inhibited EV71-induced plaque formation and apoptosis.

Pueraria lobata (Ge Gen) is commonly used for the treatment of cold, fever, and dysentery [44]. P. lobata exhibited antidiabetic, anti-inflammatory, antioxidant, 


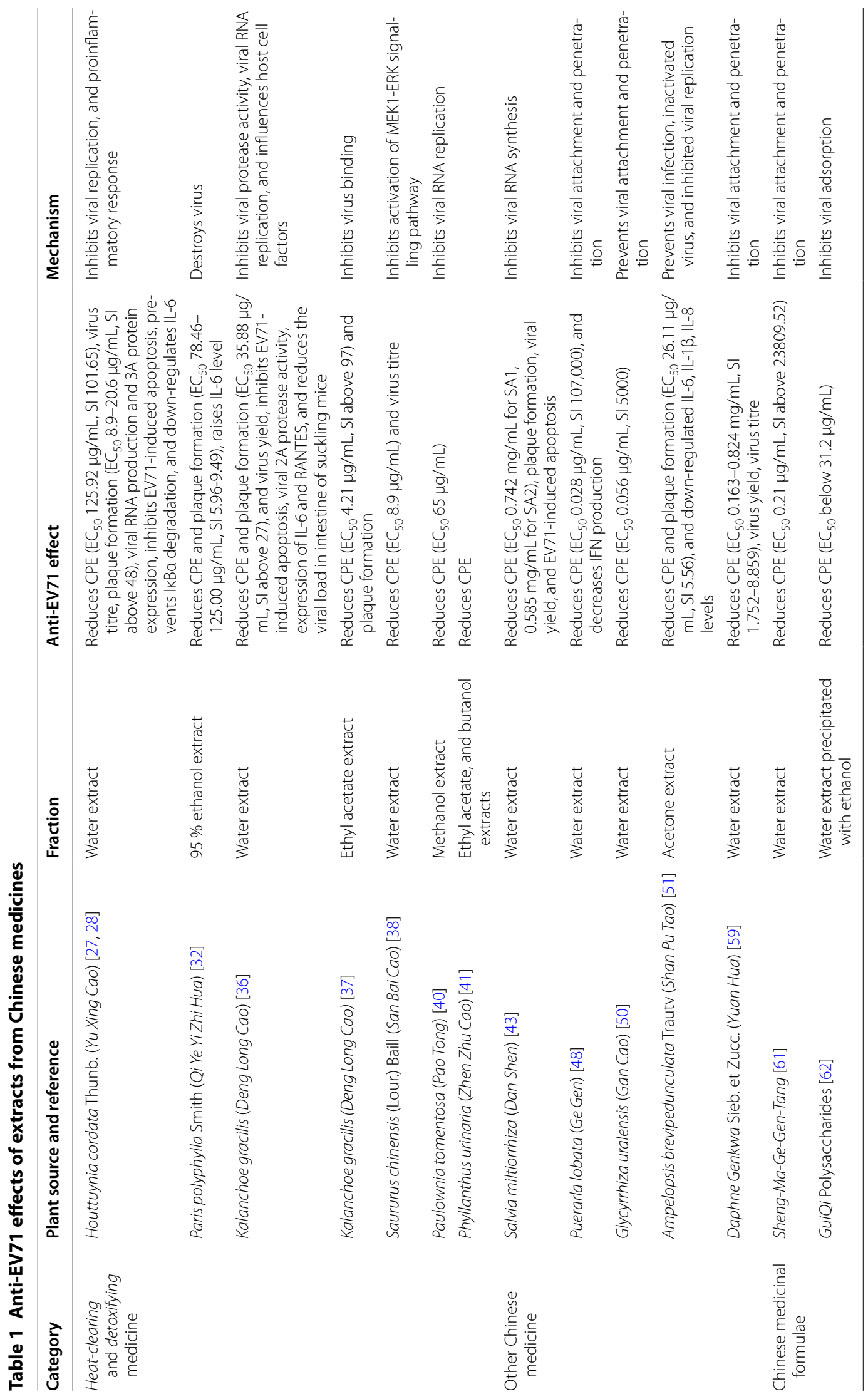


and antiviral activities against respiratory syncytial virus (RSV) [45-47]. The water extract of P. lobata, which is the main component of Ge Gen Tang, inhibited the CPE induced by EV71 when given before, simultaneously with, or after infection, with an $\mathrm{EC}_{50}$ of $0.028 \mu \mathrm{g} / \mathrm{mL}$ and an SI of $>107,000$ in a human foreskin fibroblast cell line [48]. The extract inhibited viral attachment and penetration of the host cell and decreased EV71-induced IFN production.

Glycyrrhiza uralensis (Gan Cao) is a tonic herb with a wide range of bioactivities, such as antiulcer, anti-inflammatory, spasmolytic, antioxidative, antiviral, anticancer, and hepatoprotective effects [49]. The water extract of G. uralensis inhibited the EV71-induced CPE in a human foreskin fibroblast cell line with an $\mathrm{EC}_{50}$ of $0.056 \mu \mathrm{g} /$ $\mathrm{mL}$, and treatment after viral infection provided a better protection rate than treatment before infection [50]. The protective mechanism might have involved the prevention of viral attachment and penetration, but did not involve activation of the IFN pathway.

Ampelopsis brevipedunculata Trautv (Shan Pu Tao) is used for the treatment of liver disease and inflammation, and as a food ingredient [51]. The herb also exhibited antioxidative, hepatoprotective, and antiviral activities toward HBV [52-54]. The extracts of A. brevipedunculata Trautv showed the most potent anti-EV71 activity among 58 Taiwanese folk medicinal plants examined [51]. The $\mathrm{EC}_{50}$ of the acetone extract was $26.11 \mu \mathrm{g} / \mathrm{mL}$, and the inhibitory effects may be related to effects on viral infection, activity, and replication. The extract may also significantly upregulate IL- 6 and IL-1 $\beta$ levels and downregulate IL-8 levels.

Daphne Genkwa Sieb. et Zucc. (Yuan Hua) is used for its diuretic, anti-inflammatory, and detoxifying effects with antioxidative activity [55]. Components isolated from $D$. Genkwa exhibited anti-inflammatory and anticancer activities [56-58]. The extract of dried buds from D. Genkwa Sieb. et Zucc. reduced the EV71-induced CPE with $\mathrm{EC}_{50}$ values of $0.163-0.824 \mathrm{mg} / \mathrm{mL}$, and exhibited strong anti-EV71 activity during the viral pre-adsorption step [59].

\section{Chinese medicinal formulae}

Sheng-Ma-Ge-Gen-Tang (SMGGT) is a Chinese formula, consisting of four herbal medicines: Rhizoma Cimicifugae (Sheng Ma), P. lobata (Ge Gen), Glycyrrhiza uralensis (Gan Cao), and Raeonia lactiflora (Shao Yao), and it is frequently used for treatment of measles, fevers and headaches; and it exhibited antiviral effects on human respiratory syncytial virus [60]. An extract of SMGGT significantly inhibited EV71-induced $\mathrm{CPE}$ with an $\mathrm{EC}_{50}$ of approximately $0.21 \mu \mathrm{g} / \mathrm{mL}$ and without toxicity at concentrations up to $5000 \mu \mathrm{g} / \mathrm{mL}$ (SI > 23809.52) [61].
The extract inhibited viral attachment and penetration, though it did not significantly change the IFN level.

GuiQi polysaccharides (GQP) are derived from the water extract and alcohol precipitation of mixtures of Angelica sinensis (Dang Gui) and Astragalus membranaceus (Huang Qi) roots in a ratio of 1:5, and this formula is used for the tonification of $q i$ and $x u e$ in the body. GQP significantly reduced EV71 induced-CPE with $\mathrm{EC}_{50}$ below $31.2 \mu \mathrm{g} / \mathrm{mL}$ and blocked EV71 adsorption rather than inhibiting EV71 replication [62].

\section{Pure compounds derived from CHMs with anti-EV71 activity}

Extracts of CHMs show a variety of bioactivities and contain diverse mixtures of essential bioactive compounds. Pure compounds with anti-EV71 activity are summarized in Table 2.

\section{Flavones}

Apigenin is widely distributed in a variety of plants, such as Ocimum basilicum (Luo Le), parsley, artichoke, basil, and celery. Apigenin showed anti-EV71 activity at approximately $25 \mu \mathrm{M}$, and inhibited viral protein expression, reactive oxygen species (ROS) generation, and cytokine upregulation [63, 64]. Apigenin also interfered with viral internal ribosome entry site (IRES) activity and JNK activation [65]. The study also suggested that apigenin inhibited the association of EV71 RNA with RNAediting-related hnRNP proteins [65].

Chrysosplenetin and penduletin are two flavonols isolated from the leaves of Laggera pterodonta (Chou Ling Dan), which is used for clearing heat and detoxification [66]. These flavonols exhibited potent anti-EV71 activity with low $\mathrm{EC}_{50}$ values of $0.20 \mu \mathrm{M}$ for chrysosplenetin and $0.17 \mu \mathrm{M}$ for penduletin, and had SI values of $>100$ [67]. The flavonols showed strong antiviral potency by targeting the viral post-attachment stage. Flavonoids with 3-methoxy, 5-hydroxy, and 4'-hydroxyl groups showed antipicornavirus activity by targeting the phosphatidylinositol 4-kinase III $\beta$ (PI4KB) pathway, and being within the same group, chrysosplenetin and penduletin might inhibit PI4KB, which would contribute to their anti-EV71 activity [68]. The PI4KB/oxysterolbinding protein (OSBP) pathway was the major target of the anti-picornavirus activity of enviroxime-like compounds and flavonoids with 3-methoxy, 5-hydroxy, and 4 '-hydroxyl groups [69-72]. Inhibition of the PI4 KB/ OSBP pathway might contribute to the anti-EV71 activity of many uncharacterized compounds [69, 73, 74]. However, as reported, consecutive administration of two different structural PI4 KB inhibitors in SJL mice exhibited certain toxicity, which limited their further application [75]. 


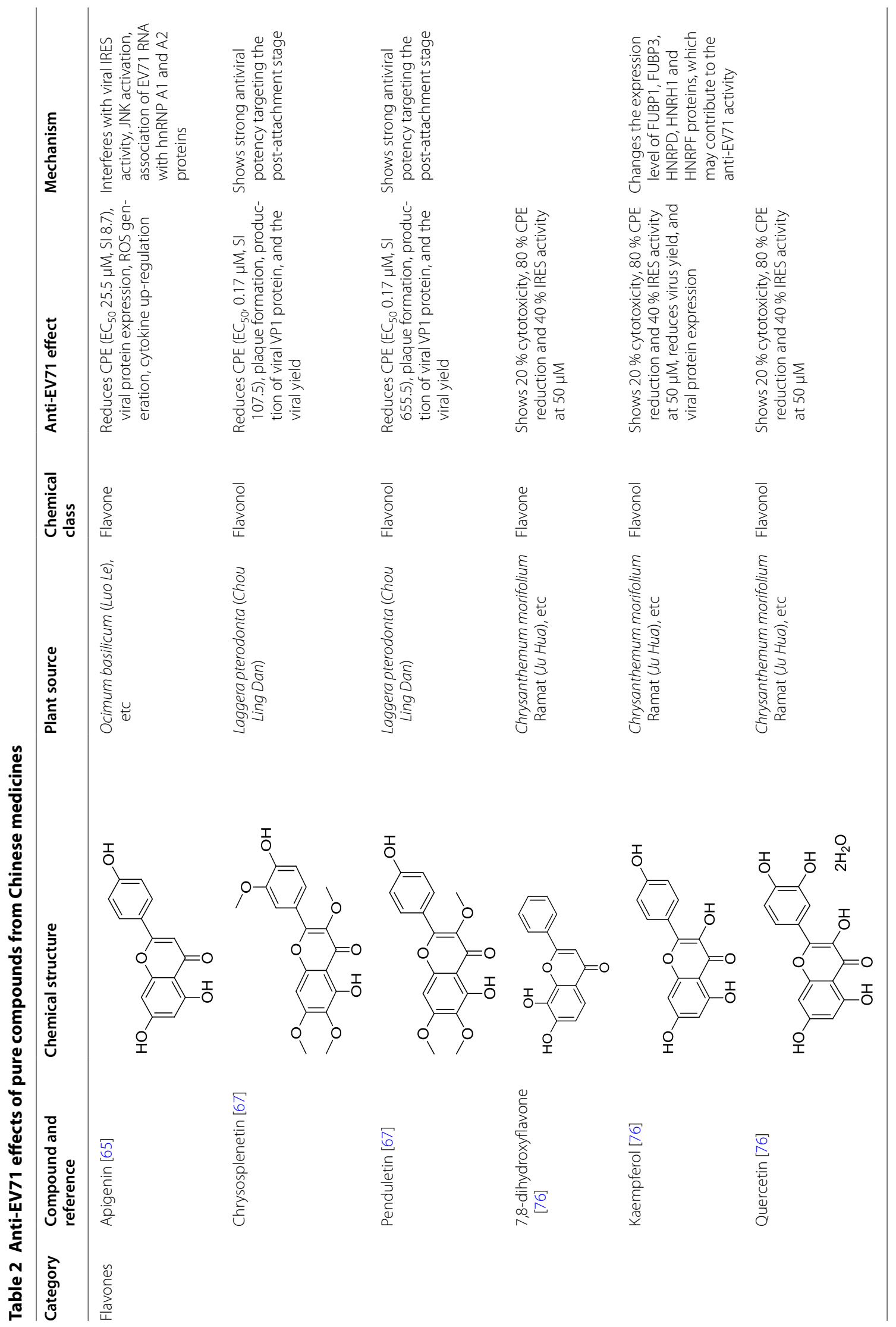




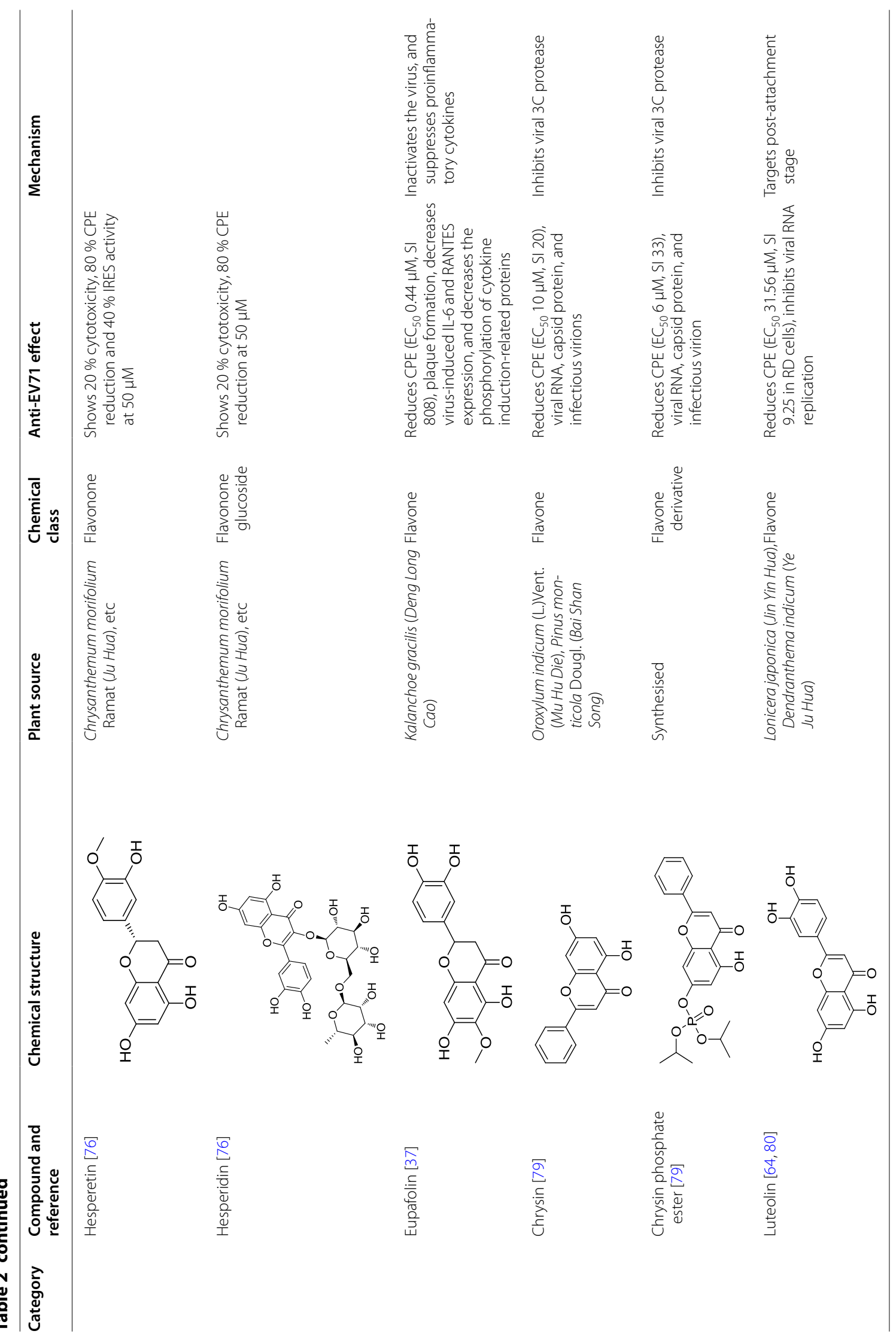




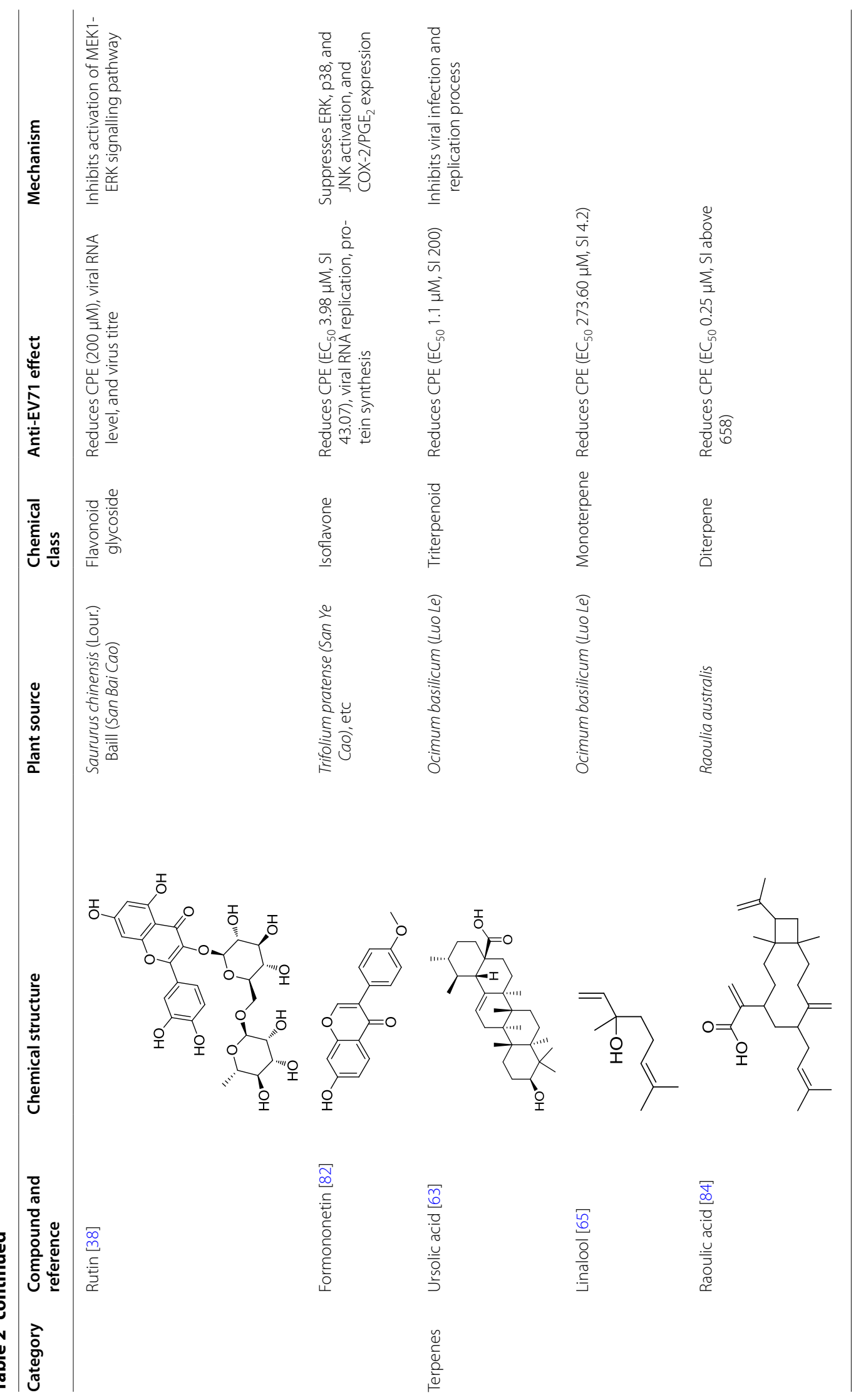




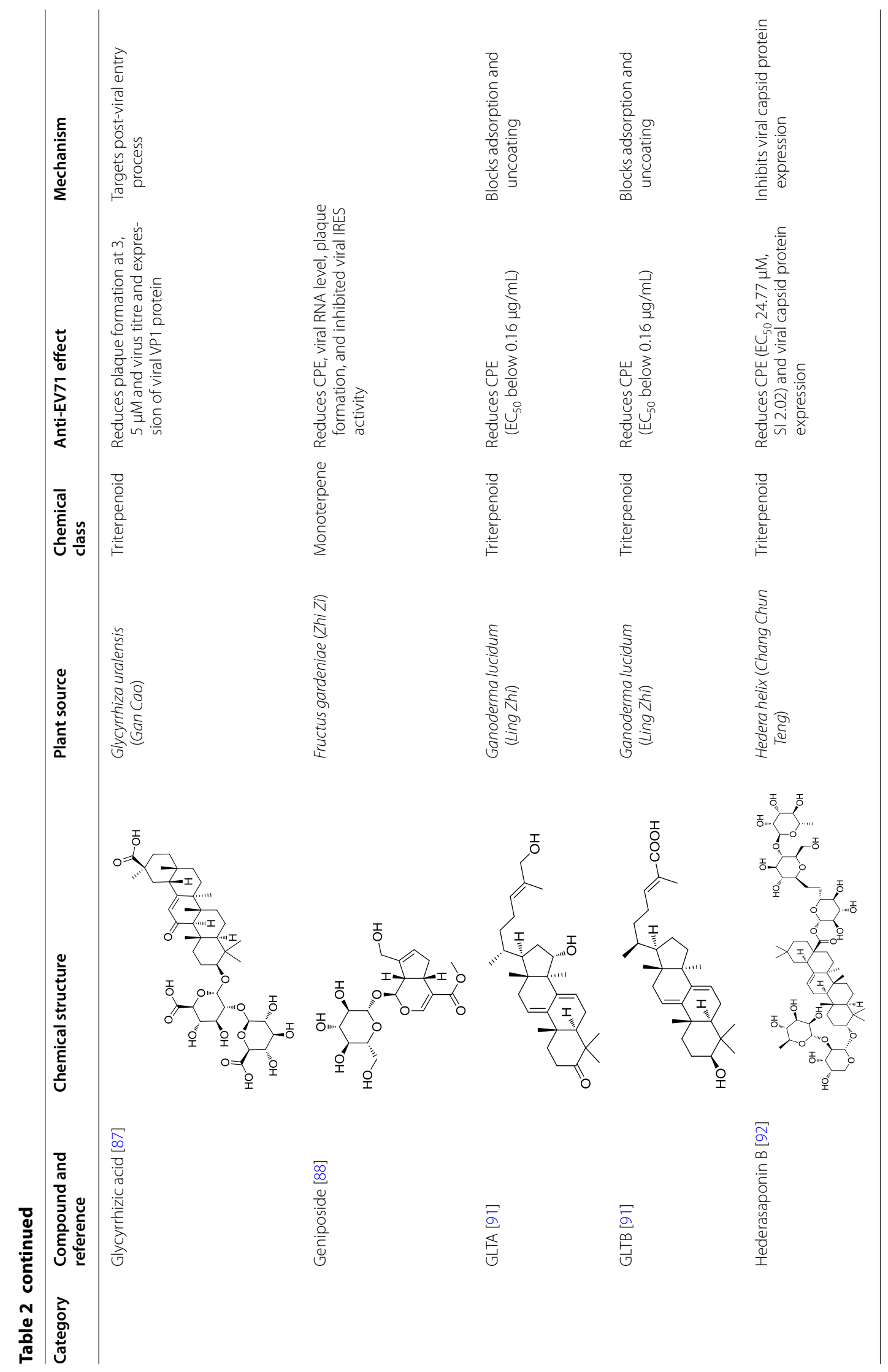




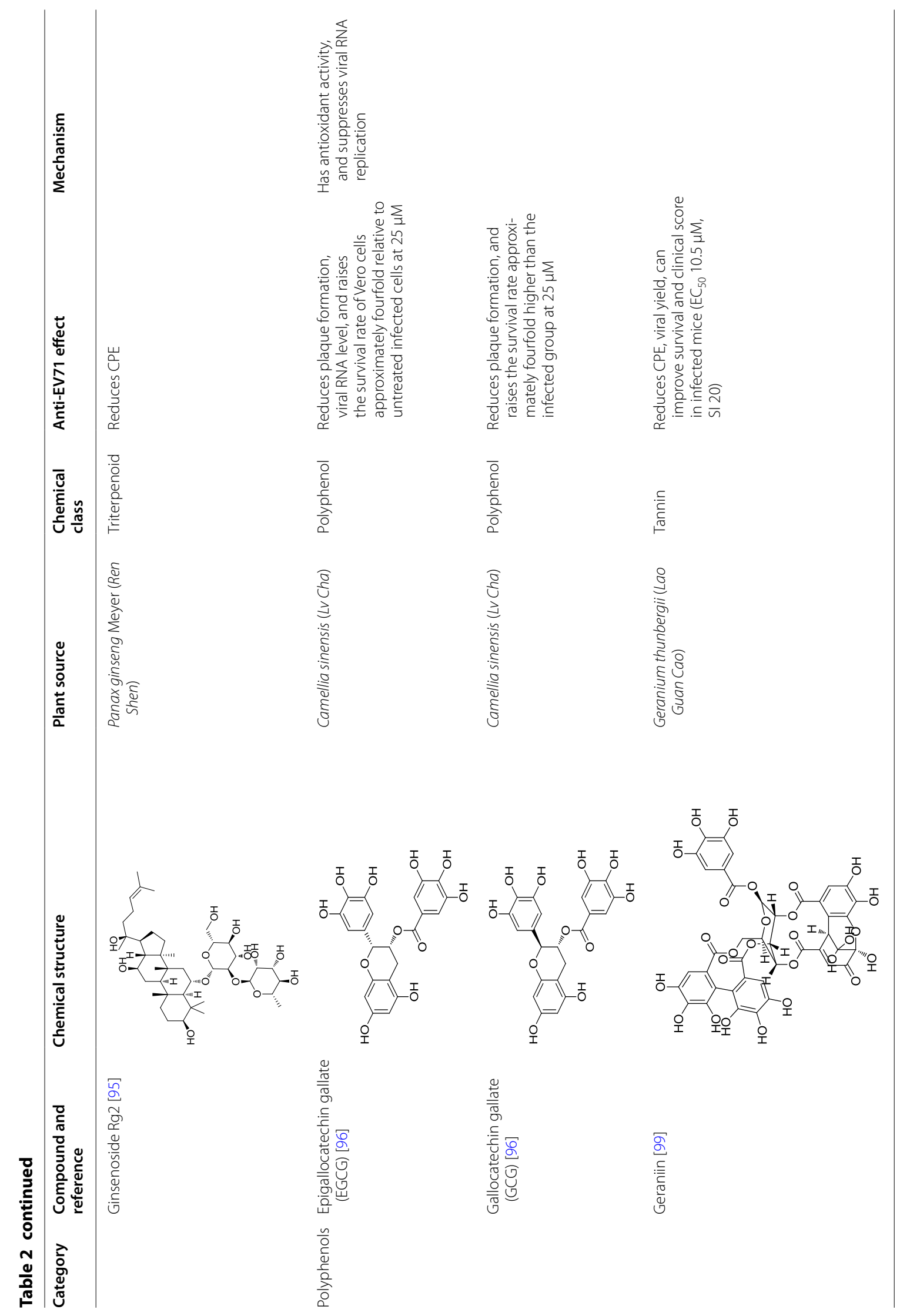




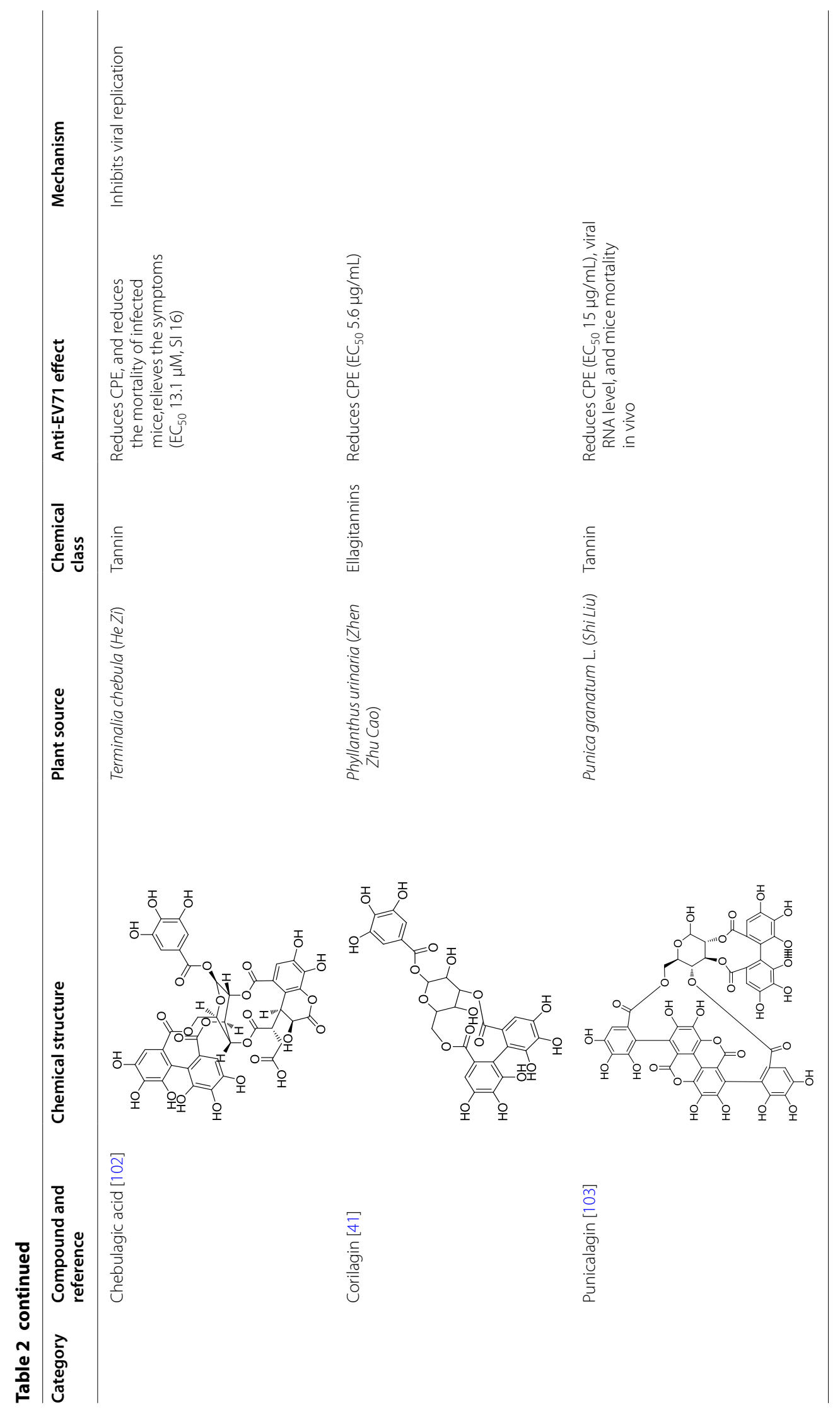




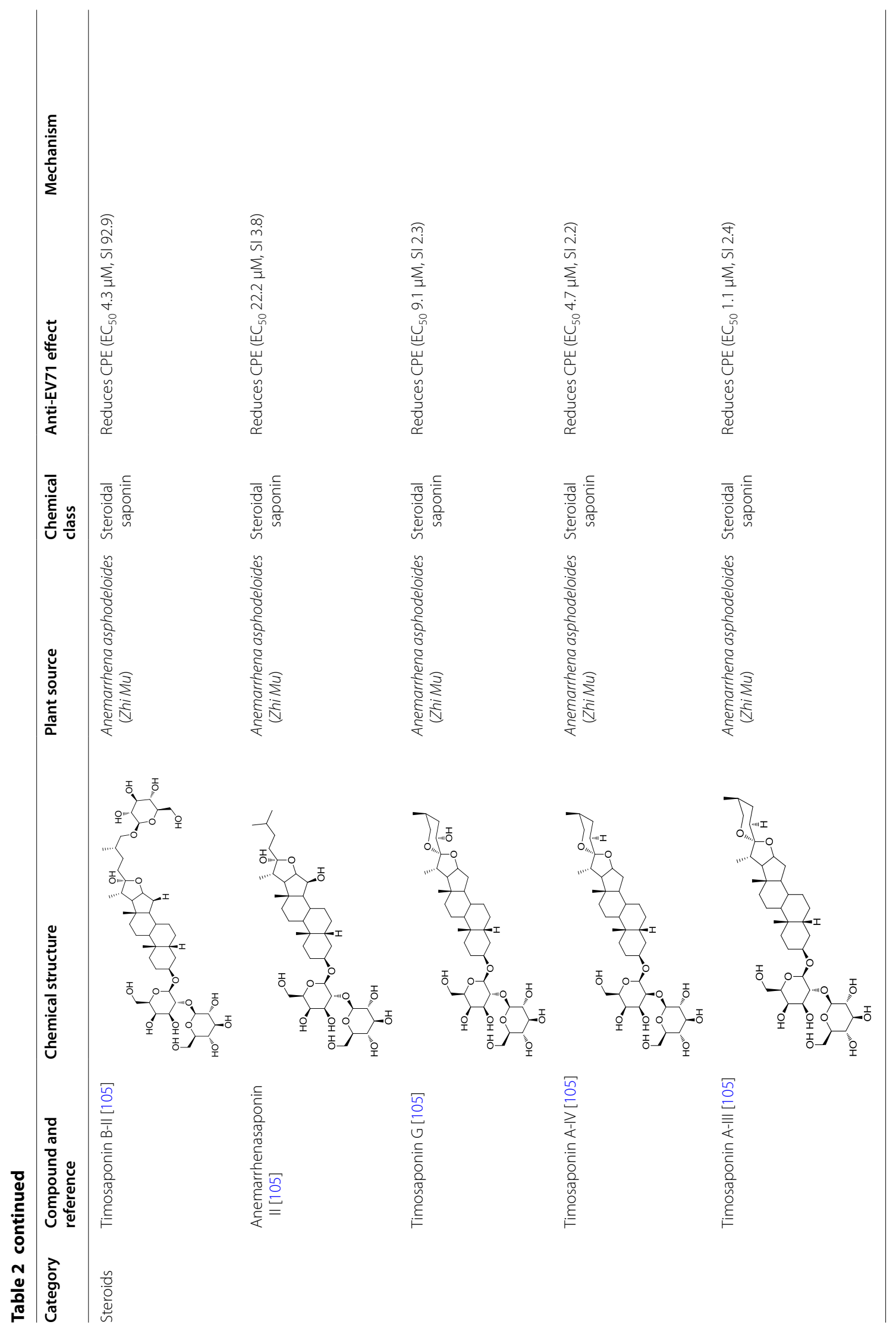




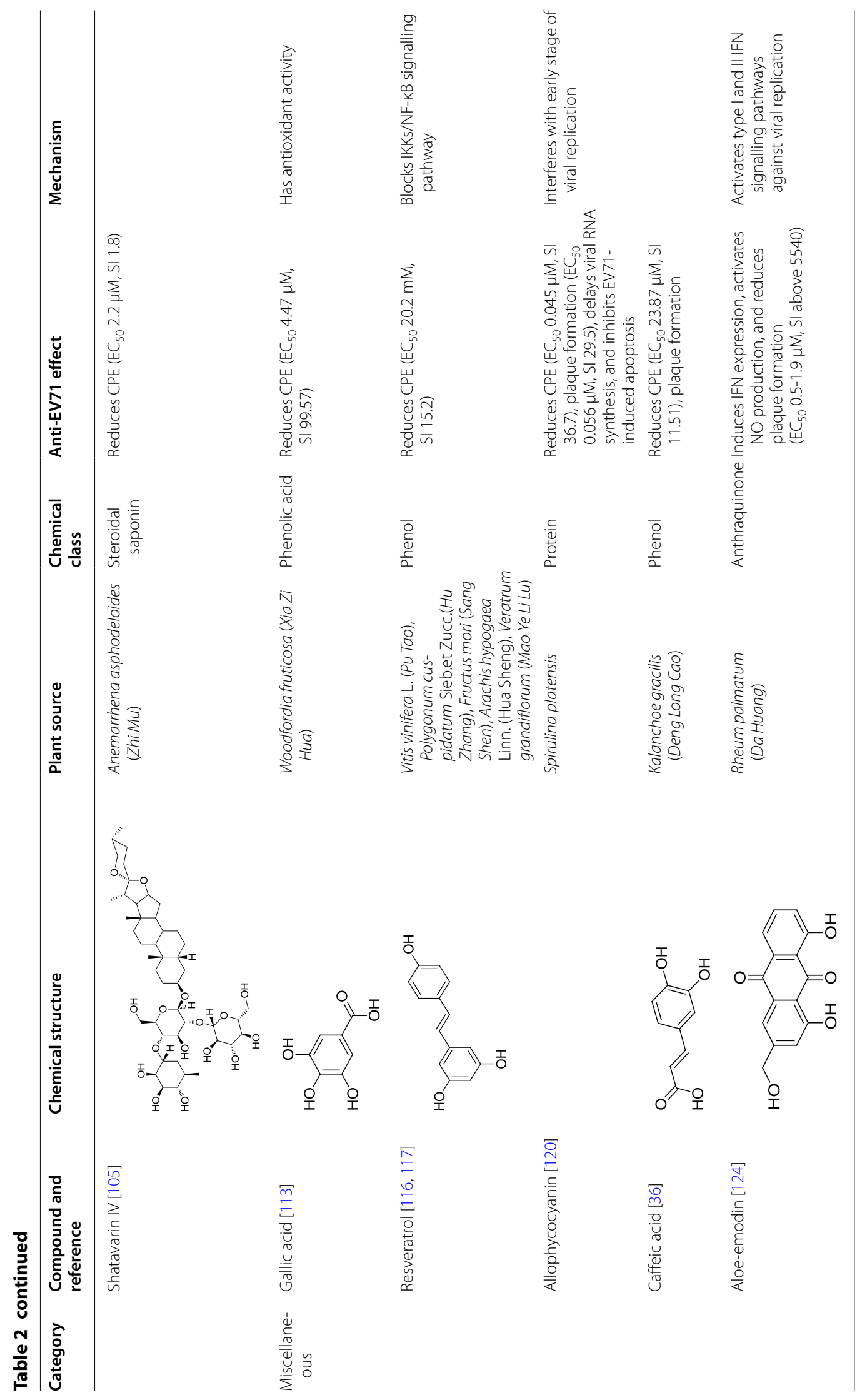




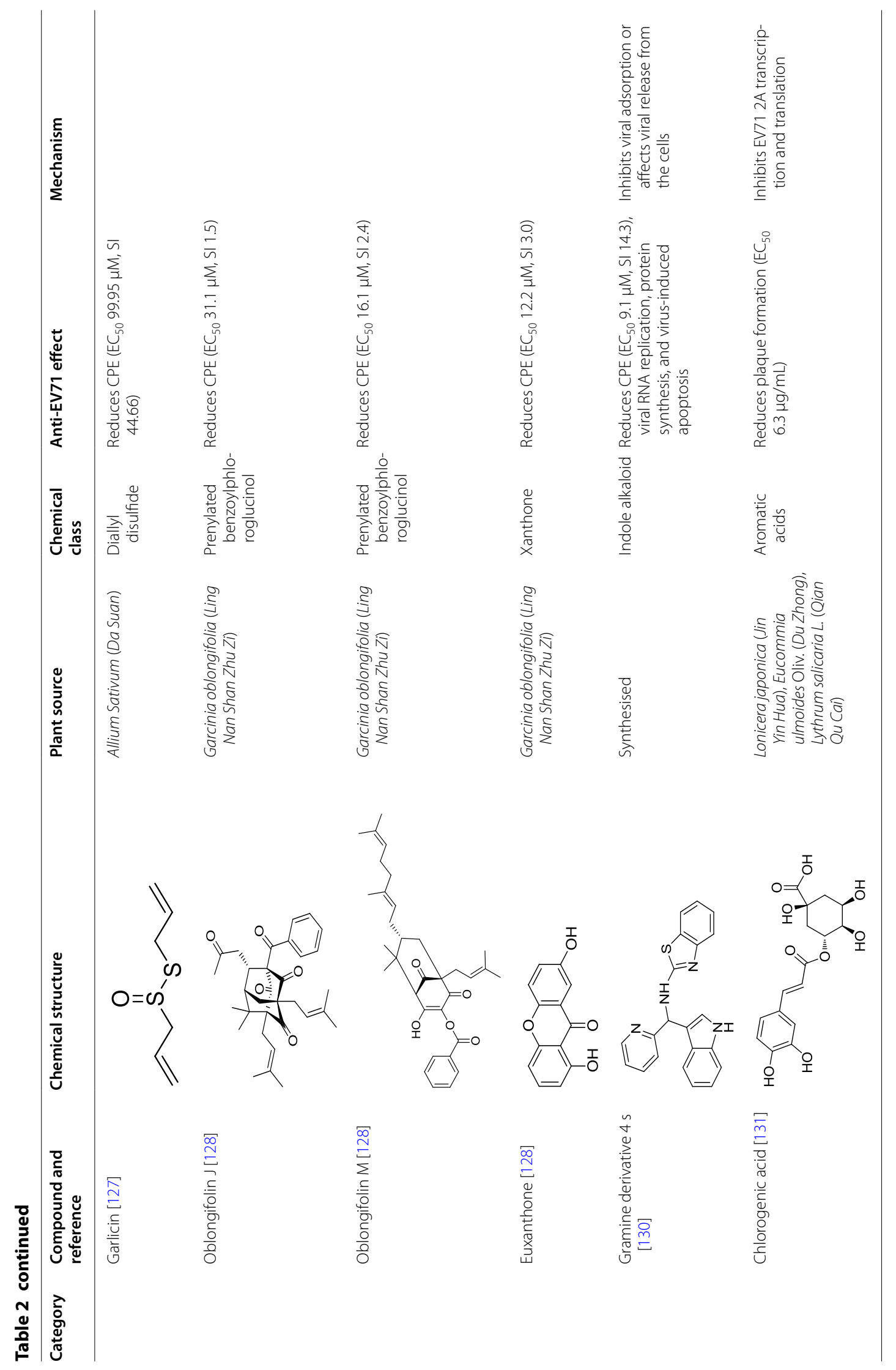




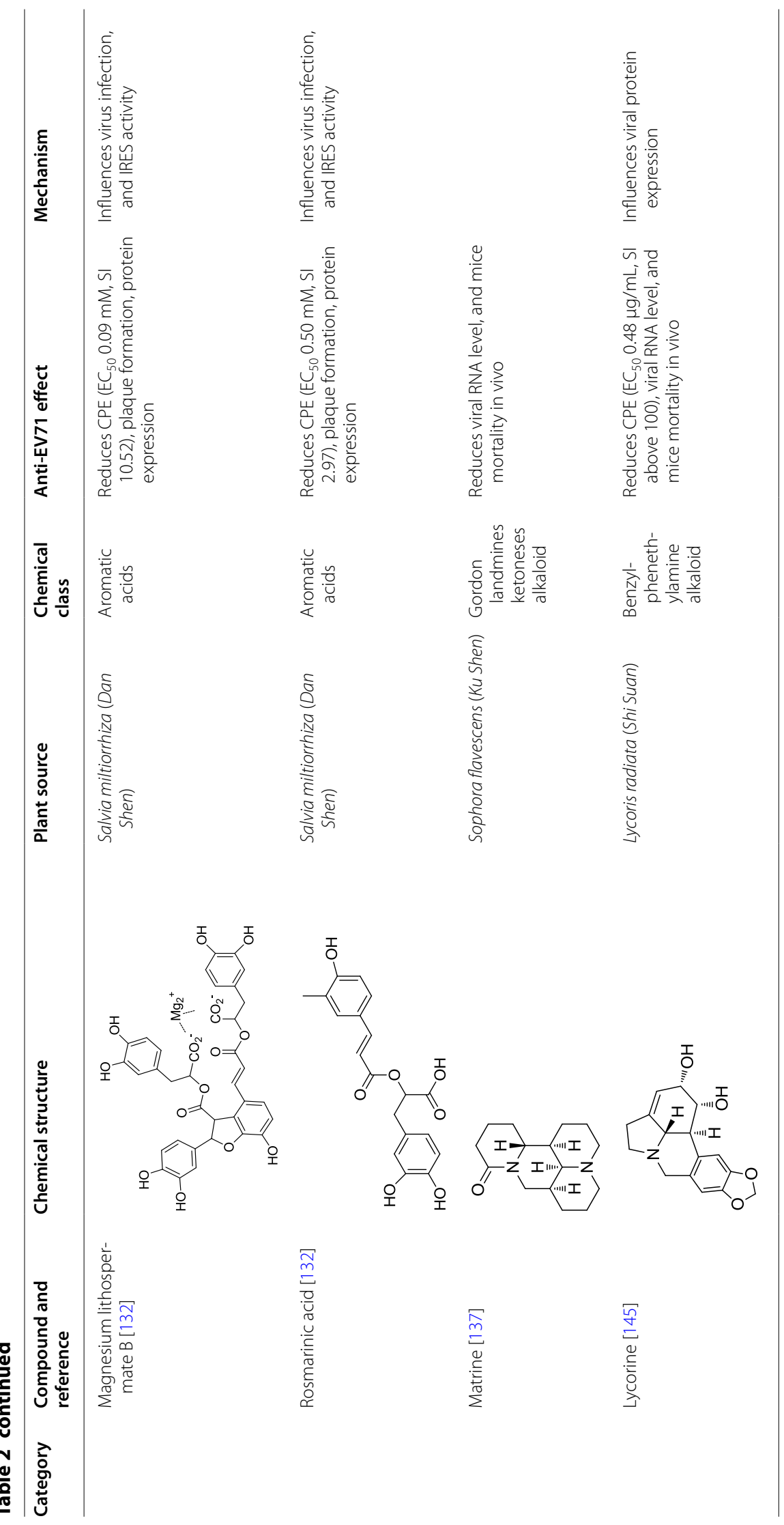


7,8-dihydroxyflavone, kaempferol, quercetin, hesperetin, and hesperidin are polyphenolic flavones with inhibitory effects on EV71 infection at a concentration of $50 \mu \mathrm{M}$ [76]. Among them, 7,8-dihydroxyflavone, kaempferol, and hesperetin inhibited $40 \%$ of viral IRES activity. Kaempferol also significantly reduced the viral yield by its regulatory effects on IRES function and EV71 replication through changes to the IRES-associated trans-acting factors FUBP1, FUBP3, HNRPD, HNRH1, and HNRPF.

Chrysin (CR) is a flavone extracted from the seeds of Oroxylum indicum (L.) Vent. (Mu Hu Die) and other plants, and exhibited antitumor and antidiabetic bioactivities $[77,78]$. CR was indicated to show possible binding to EV71 protease 3C in Autodock 4.0 simulations [79]. CR exhibited strong anti-EV71 activity with an $\mathrm{EC}_{50}$ of $10 \mu \mathrm{M}$ in CPE inhibition assays, while its phosphate ester (CPI) showed a more potent effect with a lower $\mathrm{EC}_{50}$ of $6 \mu \mathrm{M}$.

Luteolin can be found in many plants, such as Lonicera japonica (Jin Yin Hua) and Perilla frutescens (L.) Britt (Bai Su). This flavonoid exhibited various pharmacological activities, including inhibition of EV71 and CVA16 with $\mathrm{EC}_{50}$ values of approximately $10 \mu \mathrm{M}$ [80]. Xu et al. [80] reported that luteolin targeted the post-attachment stage of EV71 and CVA16 infection by inhibiting viral RNA replication, while $\mathrm{Lv}$ et al. [64] reported that it might act on viral polyprotein expression after viral entry of EV71, and prevent EV71-induced cell apoptosis, intracellular ROS generation, and cytokine upregulation.

Formononetin can be extracted from many herbs and plants, such as leguminous plants [81]. It exhibited various bioactivities including anti-inflammatory, antioxidative, and anticancer effects [82]. In a large-scale screening, formononetin demonstrated significant anti-EV71 activity [82]. Specifically, it inhibited the EV71-induced CPE with an $\mathrm{EC}_{50}$ of $3.98 \mu \mathrm{M}$, reduced virus RNA replication and protein expression in a dose-dependent manner, and exerted antiviral activity by application before and after EV71 infection. The mechanism of the formononetin activity involved the suppression of ERK, p38 MAPK, and JNK activation as well as the suppression of EV71induced $\mathrm{COX}-2 / \mathrm{PGE}_{2}$ expression.

\section{Terpenes}

Raoulic acid is the main component of Raoulia australis, a perennial shrub plant from New Zealand. Raoulic acid reduced the EV71-induced CPE [83], and possessed broad-spectrum antiviral activity against six HRVs with $\mathrm{EC}_{50}$ values of less than $0.1 \mu \mathrm{g} / \mathrm{mL}$ [84].

Ursolic acid from $O$. basilicum was reported to possess antitumor activity [85]. It showed strong anti-EV71 activity with an $\mathrm{EC}_{50}$ of $1.1 \mu \mathrm{M}$ and SI of $>200$, and might inhibit viral infection and replication processes [63].
Glycyrrhizic acid is a major bioactive compound found in G. uralensis (Gan Cao), which is used for the treatment of sore throat, cough, peptic ulcers, and other ailments in CM [49]. The compound exhibited anti-inflammatory, antidiabetic, antioxidative, anticancer, anti-microbial, and antiviral properties [86]. Glycyrrhizic acid suppressed the EV71-induced CPE and plaque formation at 3 and $5 \mathrm{mM}$, respectively, and might target post-viral entry processes [87].

Geniposide is a primary component of Fructus gardeniae $(Z h i Z i)$, a fruit that can be used for its laxity and anti-inflammatory effects [88]. Geniposide protected more than $80 \%$ of cells against EV71 infection at a concentration of $3 \mathrm{mg} / \mathrm{mL}$, and reduced the EV71-induced CPE by approximately $80 \%$ at a concentration of $2 \mathrm{mg} /$ $\mathrm{mL}$ [89]. Geniposide might block the translation of viral proteins.

Lanosta-7,9(11),24-trien-3-one,15,26-dihydroxy (GLTA) and ganoderic acid Y (GLTB) are two triterpenoids from Ganoderma lucidum (Ling Zhi), which is widely used in CM to treat a variety of diseases and has potential for bioremediation [90]. These triterpenoids reduced the EV71-induced $\mathrm{CPE}$ with $\mathrm{EC}_{50}$ values of $<0.16 \mu \mathrm{g} / \mathrm{mL}$ and blocked viral particle uncoating [91].

Hederasaponin B can be isolated from Hedera helix (Chang Chun Teng). The isolate inhibited the CPE induced by the $\mathrm{C} 3$ and C4a types of EV71 with $\mathrm{EC}_{50}$ values of $<0.16 \mu \mathrm{g} / \mathrm{mL}$ and reduced viral capsid protein expression [92].

Ginsenosides are major active components of Panax ginseng Meyer (Ren Shen). Ginsenosides possesses antiaging, antidiabetic, anticancer, and antiviral activities [93, 94]. In a cell-based screening of seven ginsenosides, a $\mathrm{CPE}$ reduction assay was applied and quantified with the sulforhodamine B method [95]. Among the substances examined in the screening, only ginsenoside Rg2 showed moderate dose-dependent anti-EV71 effects.

\section{Polyphenols}

Epigallocatechin gallate (EGCG) and gallocatechin gallate (GCG) are two tea catechins that significantly reduced EV71-induced plaque formation, while EGCG also reduced the viral RNA levels of EV71 [96]. EGCG and GCG at concentrations of $25 \mu \mathrm{M}$ increased the cell survival rate by approximately fourfold compared with the rate in mock-infected Vero cells. The anti-oxidative activity of EGCG might contribute to the anti-EV71 activity.

Geraniin derived from Geranium thunbergii (Lao Guan Cao) possessed anti-bacterial, anti-diarrheal, antioxidative, and anti-hypertensive effects, and induced cell death [97, 98]. Geraniin reduced the EV71-induced CPE in vitro with an $\mathrm{EC}_{50}$ of $10.5 \mu \mathrm{M}$ and improved the survival rate and clinical score of EV71-infected mice [99]. 
Chebulagic acid, a hydrolysable tannin, is isolated from the fruits of Terminalia chebula ( $\mathrm{He} \mathrm{Zi}$ ), and used for its spasmolytic, anti-diarrheal, anti-bacterial, anti-hyperglycemic, and broad-spectrum antiviral activities [100, 101]. Chebulagic acid showed anti-EV71 activity in vitro with an $\mathrm{EC}_{50}$ of $13.1 \mu \mathrm{M}$, and reduced the mortality and relieved the symptoms of EV71-infected mice by inhibiting viral replication in vivo [102].

Punicalagin was examined for its antiviral effects, and reduced both the CPE and viral RNA levels in vitro with an $\mathrm{EC}_{50}$ of $15 \mu \mathrm{g} / \mathrm{mL}$. Furthermore, punicalagin reduced the mortality and relieved the clinical symptoms, such as hind limb paralysis, of mice in vivo [103].

\section{Steroids}

Components of Anemarrhena asphodeloides ( $\mathrm{Zhi} M u$ ) exhibited significant pharmacological effects on the nervous system and blood, and displayed antitumor, antioxidative, antimicrobial, antiviral, anti-inflammatory, antiosteoporotic, skin-protective, and anti-aging effects [104]. By applying an isolation method called folding fan mode counter-current chromatography and CPE reduction assays, six anti-EV71 saponins were identified in $A$. asphodeloides, among which timosaponin B-II displayed the best medicinal potential with an $\mathrm{EC}_{50}$ of $4.3 \mu \mathrm{M}$ and the highest SI of 92.9 [105]. Further improvements of the isolation method were achieved using two-phase solvent systems in sample pre-treatment, which increased the production yield of the active compound [106].

\section{Miscellaneous}

Gallic acid is a component of Woodfordia fruticosa flowers (Xia Zi Hua), which are used to treat dysentery and irregular menstruation, and exhibited antibacterial, hepatoprotective, and immunostimulatory effects [107-109]. Gallic acid also exhibited antibacterial, antiinflammatory, antiallergic, and neuroprotective effects [110-112] and showed an inhibitory effect on the EV71induced CPE in Vero cells with an $\mathrm{EC}_{50}$ of $4.47 \mu \mathrm{M}$ [113].

Resveratrol is contained in grapes, mulberries, peanuts, Polygonum cuspidatum (Hu Zhang), and several other sources. Resveratrol exhibited antioxidant and antiinflammatory activities and improved glucose and lipid metabolism [114]. Resveratrol also acted on cardiovascular parameters and modified some pathways involved in carcinogenesis [115]. Resveratrol increased the survival rate of EV71-infected Vero cells with an $\mathrm{EC}_{50}$ of $20.2 \mathrm{mM}$ and SI of 15.2 [116]. Resveratrol inhibited the virus titer and protein expression by blocking the IKK/NF- $\mathrm{KB}$ signaling pathway [117]. However, polydatin is the most abundant form of resveratrol that exists naturally, and this compound did not show significant anti-EV71 activity.
Allophycocyanin is a fluorescent protein derived from the blue-green alga Spirulina platensis, and exhibited antioxidant and anticancer activities $[118,119]$. The protein exerted anti-EV71 activity in CPE and plaque reduction assays with an $\mathrm{EC}_{50}$ of $0.045 \mu \mathrm{M}$, delayed viral RNA synthesis, and inhibited EV71-induced apoptosis [120]. Allophycocyanin also showed antiviral activity against CVA16.

Aloe-emodin is a free anthraquinone isolated from Rheum palmatum (Da Huang) that is used for purgation, clearing heat, and detoxification, and exhibited antibacterial, hepatoprotective, antitumor and antiangiogenic effects [121-123]. Aloe-emodin showed antiviral activity against EV71 in HL-CZ and TE-671 cells with $\mathrm{EC}_{50}$ values of $0.5-1.9 \mu \mathrm{M}$ [124]. Aloe-emodin induced the expression of IFNs, and might be involved in the activation of the type I and II IFN signaling pathways against viral replication.

Garlicin, a component of Allium sativum (Da Suan), is a commonly used food ingredient in Asia. A. sativum has antimicrobial, anticancer, antidiabetic, anti-fatigue, and blood pressure-reducing effects [125, 126]. Garlicin inhibited the EV71-induced CPE in Vero cells with an $\mathrm{EC}_{50}$ of $99.95 \mu \mathrm{M}$ [127].

Oblongifolin J, oblongifolin $\mathrm{M}$, and euxanthone are isolated from the leaves of Garcinia oblongifolia Champ. ex Benth (Ling Nan Shan Zhu Zi), which have anti-inflammatory and analgesic activities and can be used to treat myogenic convergence, allergies, rash, itching, ulcers, hepatitis, laryngitis, and hemoptysis. The isolates inhibited the CPE in EV71-infected Vero cells with $\mathrm{EC}_{50}$ values of 31.1, 16.1, and $12.2 \mu \mathrm{M}$, respectively [128].

Gramine, a natural indole alkaloid, can be isolated from various raw plants and coal tar, and exhibited broad pharmaceutical activities, such as relaxation of bronchial smooth muscle, vasorelaxation, blood pressure elevation, relief of bronchitis nephritis, and relief of bronchial asthma [129]. Gramine did not exhibit anti-EV71 activity [129]. However, Wei et al. [130] performed a series of chemical modifications on gramine, and showed that 18 of 21 derivatives displayed some degree of anti-EV71 effect. Among the derivatives, $4 \mathrm{~s}$ had a relatively low $\mathrm{EC}_{50}$ of $9.1 \mu \mathrm{M}$ and the highest SI of 14.3. In their study, $4 \mathrm{~s}$ inhibited the virus-induced cell apoptosis, viral RNA replication, and viral protein expression, and may therefore target the early stage of the EV71 lifecycle.

Chlorogenic acid is a major active component of many CHMs, including Eucommia ulmoides Oliv. (Du Zhong), L. japonica Thumb. (Jin Yin Hua), and Polygonum aviculare L. (Bian Xu). Chlorogenic acid reduced EV71induced plaque formation with an $\mathrm{EC}_{50}$ of $6.3 \mu \mathrm{g} / \mathrm{mL}$, inhibited viral protein $2 \mathrm{~A}$ transcription and translation, 
and downregulated IL-6, TNF- $\alpha$, IFN- $\gamma$, and MCP-1 secretion in EV71-infected RD cells [131].

Magnesium lithospermate B (MLB) and rosmarinic acid (RA) are two compounds found in S. miltiorrhiza. The results from pGS-EV71 IRES-based bicistronic reporter assays suggested that MLB and RA inhibited EV71 IRES activity [132], and further inhibited the EV71induced $\mathrm{CPE}$ with $\mathrm{EC}_{50}$ values of 0.09 and $0.50 \mathrm{mM}$, plaque formation, and viral protein expression. These compounds exerted their antiviral effects during the viral absorption stage.

Matrine is isolated from Sophora flavescens (Ku Shen), and used for its heat-clearing and detoxifying properties. Matrine exhibited anticancer, antidiabetic, hepatoprotective, and cardioprotective effects [133-136]. It also showed significant inhibitory effects on EV71 in vitro and in vivo [137]. Matrine reduced the viral RNA levels in RD cells, and protected mice from a lethal dose of EV71 virus while relieving the clinical symptoms of infection.

As one of the most abundant alkaloids in the Amaryllidaceae family, lycorine exhibited anticancer and anti-inflammatory properties and conferred antiviral effects against human immunodeficiency virus (HIV), hepatitis C virus, and HSV-1 [138-144]. In RD cells, lycorine exhibited a dose-dependent reduction of the EV71-induced CPE with an $\mathrm{EC}_{50}$ of $0.48 \mu \mathrm{g} / \mathrm{mL}$. Treatment of cells with $1.0 \mu \mathrm{g} / \mathrm{mL}$ lycorine significantly inhibited the viral RNA level. The antiviral mechanism might be related to interference with viral polyprotein translation. Lycorine inhibited EV71 replication in muscle tissues of mice, resulting in reduced mortality, dosedependent increases in clinical scores, and reduced pathological changes including virions in tissues, moderate inflammation, and necrotizing myositis in muscle [145].

\section{Application of CM in treatment of HFMD}

In the past three decades, there have been several outbreaks of HFMD in Taiwan, Singapore, Australia, Japan, and China, leading to millions of infections and thousands of deaths [2,146-149]. EV71 is mainly responsible for the severe symptoms caused by HFMD. No specific antiviral agent is available, making clinical management of HFMD largely supportive in nature [150]. The Ministry of Health of China issued "Guidelines for the diagnosis and treatment of hand, foot, and mouth disease" in 2010, and recommended a series of CHMs for the treatment of HFMD [151].

According to CM syndrome differentiation, HFMD has been classified into different groups with corresponding CM treatment recommendations (Table 3).

For general cases, decoctions with effects of clearing heat, dampness, and toxicity were recommended, including Forsythia suspense (Lian Qiao), L. japonica
(Jin Yin Hua), Scutellaria baicalensis (Huang Qin), Artemisia apiacea (Qing Hao), and Fructus arctii (Niu Bang $\mathrm{Zi}$ ), as well as tonic medicines such as G. uralensis (Gan Cao) and red peony root (Paeoniae rubrathe) (Chi Shao), and diuretic medicines such as barley (Semen coicis) (Yi $\mathrm{Mi}$ ). For severe cases involving symptoms such as convulsions, CM preparations that soothe the nerves were recommended, such as Uncaria tomentosa (Gou Teng), Gastrodia elata (Tian Ma), silkworm larvae (Bai Jiang Can), and concha ostreae (Ostrea gigas thunberg) (Sheng $\mathrm{Mu} \mathrm{Li}$ ). In urgent cases, potent tonic medicines such as $P$. ginseng (Ren Shen) and Aconiti carmichaeli ( $\mathrm{Fu} \mathrm{Zi}$ ) were recommended for use with caution. For oropharyngeal ulcers, several CM powders were recommended to alleviate the symptoms, and for HFMD-induced combined flaccid paralysis associated with the recovery period, acupuncture and massage were recommended for inclusion in the treatment.

Although the Chinese Government recommended these CMs in the clinical treatment of HFMD, insufficient evidence is available to support their extensive application.

$X i$ Yan Ping injection is composed mainly of andrographolide sulfonate, which is used clinically to treat bronchitis, amygdalitis, and bacillary dysentery. Andrographolide is a diterpene lactone with a variety of bioactivities, including anti-inflammatory, anticancer, and immunoregulatory effects, and is isolated from Andrographis paniculata (Burm) Nees. (Chuan Xin Lian), a heat-clearing and detoxifying medicine. Andrographolide prevented infectious diseases by inhibiting the multiplication of infectious agents, including Pseudomonas aeruginosa, Escherichia coli, Candida albicans, influenza virus, RSV, and adenovirus [152]. In 2012, a review article on the clinical application and research progress of CMs in the treatment of HFMD was published [153], in which the research progress on application of CM to the treatment of HFMD was systematically analyzed. In their study, 76 trials were included, and 18 trials met the criteria for inclusion in a meta-analysis. Compared with conventional therapy, $X i$ Yan Ping injection significantly reduced the time required for fever clearance and the skin eruption-eliminating time, with no obvious side effects [154]. A further study provided evidence that andrographolide sulfonate decreased ROS production in vitro by inhibiting lipopolysaccharide-stimulated neutrophil activation, while at 5 days post-medication with andrographolide sulfonate, the plasma myeloperoxidase, S100A8/A9, histone, and IL-6 levels were markedly lower in the combination therapy group than in the conventional therapy group [155].

Yan $\mathrm{Hu}$ Ning injection is composed of potassium sodium dehydroandrographolide succinate, with 
Table 3 Chinese medicines recommended for the treatment of HMFD by the Chinese government

\begin{tabular}{lll}
\hline $\begin{array}{l}\text { Classification } \\
\text { of HMFD }\end{array}$ & CM syndrome & Chinese medicine
\end{tabular}

General Dampness and heat in lung and spleen Gan Lu Xiao Du Dan decoction

Forsythia suspense (Lian Qiao), Lonicera japonica (Jin Yin Hua), Scutellaria baicalensis (Huang Qin), Artemisia apiacea (Qing Hao), Fructus Arctii (Niu Bang Zi), Agastache rugosa (Huo Xiang), Eupatorium fortune (Pei Lan), Ricepaperplant Pith (Tong Cao), barley (Yi Mi), talcum (Hua Shi), Glycyrrhiza uralensis (Gan Cao), Imperata cylindrical (Bai Mao Gen)

Lan Qin oral liquid

Xiao Er Chi Qiao Qing Re granule

Kang Bing Du oral liquid

Stagnation and steaming of damp-heat

Qing Wen Bai Du decoction

Xin Xue Dan

Re Du Ning injection

Xi Yan Ping injection

Dan Shen injection
Indigowoad root (Ban Lan Gen), Scutellaria baicalensis (Huang Qin), Gardenia jasminoides Ellis (Zhi Zi), Phellodendron amurense (Huang Bai), Sterculia lychnophora (Pang Da Hai)

Forsythia suspense (Lian Qiao), Semen Sojae Praeparatum (Dan Dou Chi), Mentha haplocalyx (Bo He), Schizonepeta (Jing Jie), Gardenia jasminoides Ellis (Zhi Zi), Rheum rhabarbarum (Da Huang), Artemisia apiacea (Qing Hao), red peony root (Chi Shao), Areca catechu (Bing Lang), Mangnolia officinalis(Hou Po), Scutellaria baicalensis (Huang Qin), Pinellia ternate (Ban Xia), Bupleurum chinense (Chai Hu), Glycyrrhiza uralensis (Gan Cao)

Jin Lian Qing Re effervescent tablets

Trollius chinensis (Jin Lian Hua), Folium isatidis (Da Qing Ye), gypsum (Shi Gao), Anemarrhena asphodeloides (Zhi Mu), Scrophularia ningpoensis (Xuan Shen), Semen armeniacae amarae (Ku Xing Ren)

Indigowoad root (Ban Lan Gen), gypsum (Shi Gao), Arbados aloe (Lu Hui), Rehmannia glutinosa (Sheng Di Huang), Curcuma aromatic (Yu Jin), Anemarrhena asphodeloides (Zhi Mu), Acorus gramineus (Shi Chang Pu), Pogostemon cablin (Guang Huo Xiang), Forsythia suspense (Lian Qiao)

Forsythia suspense (Lian Qiao), Gardenia jasminoides Ellis (Zhi Zi), Scutellaria baicalensis (Huang Qin), Coptis chinensis (Huang Lian), gypsum (Shi Gao), Anemarrhena asphodeloides (Zhi Mu), Salivia chinensis (Dan Pi), red peony root (Chi Shao), barley (Yi Mi), Dioscoreae hypoglaucae (Chuan Bi Xie), buffalo horn (Shui Niu Jiao)

Lodestone (Ci Shi), gypsum (Shi Gao), talcum (Hua Shi), gypsum rubrum (Han Shui Shi), saltpeter (Xiao Shi), mirabilite (Mang Xiao), Gardenia jasminoides Ellis (Zhi Zi), Lophatherum gracile (Dan Zhu Ye), Cimicifugae foetidae (Sheng Ma), Andrographis paniculata (Chuan Xin Lian), pearl powder(Zhen Zhu Ceng Fen), Lignum aquilariae resinatrm (Chen Xiang), calculus bovis (Niu Huang), borneol (Bing Pian)

Artemisia apiacea (Qing Hao), Lonicera japonica (Jin Yin Hua), Gardenia jasminoides Ellis (Zhi Zi)

Andrographolide sulfonate

Salvia miltiorrhiza (Dan Shen) 
Table 3 continued

\section{Classification of HMFD}

\section{CM syndrome}

Toxic-heat stirring wind

An Gong Niu Huang Wan

Xin Xue Dan

Re Du Ning injection

Tan Re Qing injection

Xi Yan Ping injection

Shen Fu decoction

Shen Mai injection

Shen Fu injection

Sheng MaiSan

Recovering

Insufficient qi yin and residue of pathogenic factors

Surgical
Qing Daisan

Shuang Liao Hou Feng San

Bing Peng San
Composition

Cornu saigae tataricae (Ling Yang Jiao),

Uncaria tomentosa (Gou Teng), Gastrodia

elata (Tian Ma), gypsum (Shi Gao), Coptis

chinensis (Huang Lian), Gardenia jasmi-

noides Ellis (Zhi Zi), Rheum rhabarbarum

(Da Huang), Flos Chrysanthemi (Ju Hua),

barley (Yi Mi), Buthus martensi kirsch

(Quan Xie), silkworm larvae (Bai Jiang

Can), concha ostreae (Sheng Mu Li)

Calculus bovis (Niu Huang), buffalo horn (Shui Niu Jiao), musk (She Xiang), borneol (Bing Pian), pearl (Zhen Zhu), cinnabar (Zhu Sha), realgar (Xiong Huang), Coptis chinensis (Huang Lian), Scutellaria baicalensis (Huang Qin), Gardenia jasminoides Ellis (Zhi Zi), Curcuma aromatic (Yu Jin)

See above

See above

Scutellaria baicalensis (Huang Qin), bear gall powder (Xiong Dan Fen), cornu gorais (Shan Yang Jiao), Lonicera japonica (Jin Yin Hua), Forsythia suspense (Lian Qiao)

See above

Panax ginseng (Ren Shen), Aconiti carmichaeli (Fu Zi), Cornus officinalis (Shan Zhu Yu)

Radix Ginseng rubra (Hong Shen), Ophiopogon japonicas (Mai Dong)

Radix Ginseng rubra (Hong Shen), Aconiti carmichaeli (Fu Zi)

Panax ginseng (Ren Shen), Schisandra chinensis (Wu Wei Zi), Ophiopogon japonicas (Mai Dong), Polygonatum odoratum (Yu Zhu), Artemisia apiacea (Qing Hao), Cydonia lagenaria Lois. (Mu Gua), Radix clematidis (Wei Ling Xian), Angelica sinensis (Dang Gui), loofah sponge (Si Gua Luo), Glycyrrhiza uralensis (Gan Cao)

Borneol (Bing Pian), Mentha haplocalyx (Bo He), Acacia catechu (Er Cha), Glycyrrhiza uralensis (Gan Cao), Coptis chinensis (Huang Lian), borax (Peng Sha), Indigo naturalis (Qing Dai), Depositum urinae Hominis (Ren Zhong Bai)

Pearl (Zhen Zhu), calculus bovis (Niu Huang), borneol (Bing Pian), Coptis chinensis (Huang Lian), Sophorae subprostratae (Shan Dou Gen), Glycyrrhiza uralensis (Gan Cao), Indigo naturalis (Qing Dai), Depositum urinae Hominis (Ren Zhong Bai), gypsum rubrum (Han Shui Shi)

Borneol (Bing Pian), borax (Peng Sha), cinnabar (Zhu Sha), weathered sodium sulfate (Xuan Ming Fen) defervescent, antibacterial, antiviral, and sedative effects. This injection promoted adrenal function in the treatment of upper respiratory tract infection, viral pneumonia, and child epidemic parotitis [156-158]. Yan Hu Ning injection reduced the time required for fever clearance and rash subsidence [153].

Re Du Ning injection, which is included in three heatclearing and detoxifying medicines, Qing Hao, Jin Yin 
$H u a$, and $Z h i Z i$, has been studied for its antiviral and anti-inflammatory effects $[159,160]$. Re Du Ning injection appeared to significantly reduce the time required for fever clearance and rash subsidence compared with conventional therapy [161].

$\mathrm{Pu} \mathrm{Di}$ Lan is prepared as oral tablets or a liquid, and mainly consists of Taraxacum mongolicum (Pu Gong Ying), S. baicalensis (Huang Qin), Corydalis bungeana Turcz. (Ku Di Ding), and Baphicacanthis cusiae Rhizoma et Radix (Ban Lan Gen). Pu Di Lan treatment possessed superior efficacy compared with conventional drug therapy in the time required for fever clearance, rash subsidence, and oral ulcer treatment [153].

\section{Non-Chinese medicine}

\section{Kappa carrageenan}

Kappa carrageenan is water-soluble, sulfated galactan existing in a variety of seaweeds and is widely applied as a food additive [162]. It showed anti-EV71 activity with little associated toxicity [163]. The anti-EV71 activity might be attributable to the direct binding of carrageenan with virus particles.

\section{Perspectives}

In recent years, attention has been increasingly drawn to the screening of natural products and especially $\mathrm{CM}$ for anti-EV71 active components. The anti-EV71 mechanisms of action of these components have been summarized in Fig. 1. Common strategies for identifying anti-EV71 components are shown in Fig. 2. One strategy is bioactivity-guided isolation, which has been represented in the isolation of Garcinia oblongifolia, Hedera helix and Anemarrhena asphodeloides. Another strategy is systematic identification of the chemical constituents from a natural source and subsequent testing of each purified compound for antiviral activity, with more time and cost consumption. Additionally, in the case where the active compound is known and a standard substance is available, a fingerprint profile can be used for identification of them in active extracts. Furthermore, chemical modification of known active natural compounds may lead to better structural optimization to yield higher efficiency and lower toxicity, thus promoting anti-EV71 drug development [130].

Development of computer simulations allows the indepth study of EV71 infection and pathogenic mechanisms; with the expansion of compound libraries, the anti-EV71 compound targeting of viral proteins becomes increasingly predictable, thus enabling direct synthesis of predicted bioactive molecules [79]. An alternative for cell-based screening involves a two-step platform that

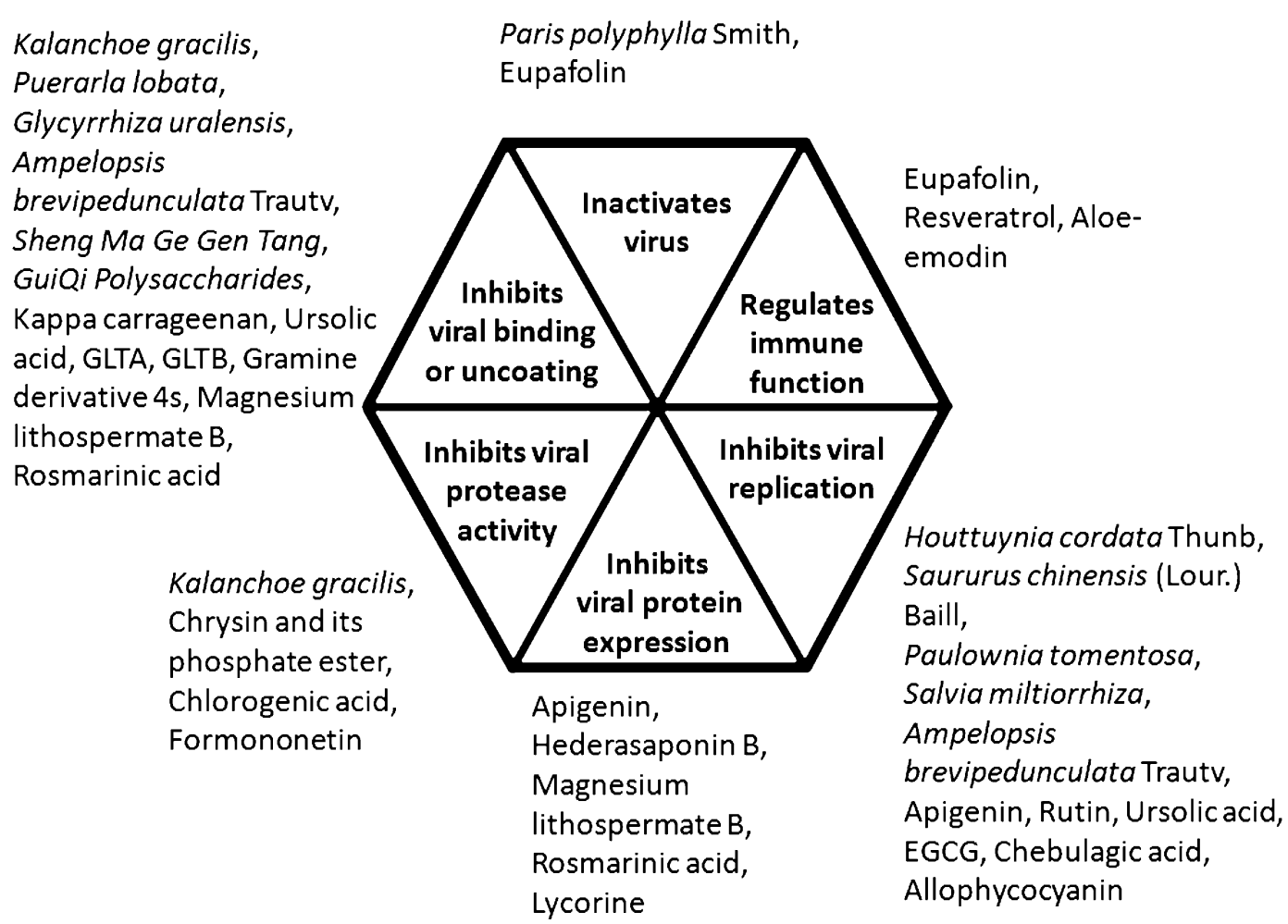

Fig. 1 Mechanisms of anti-EV71 components. Mechanisms of anti-EV71 activities associated with the shown CM-derived extracts and molecules were classified into six categories 


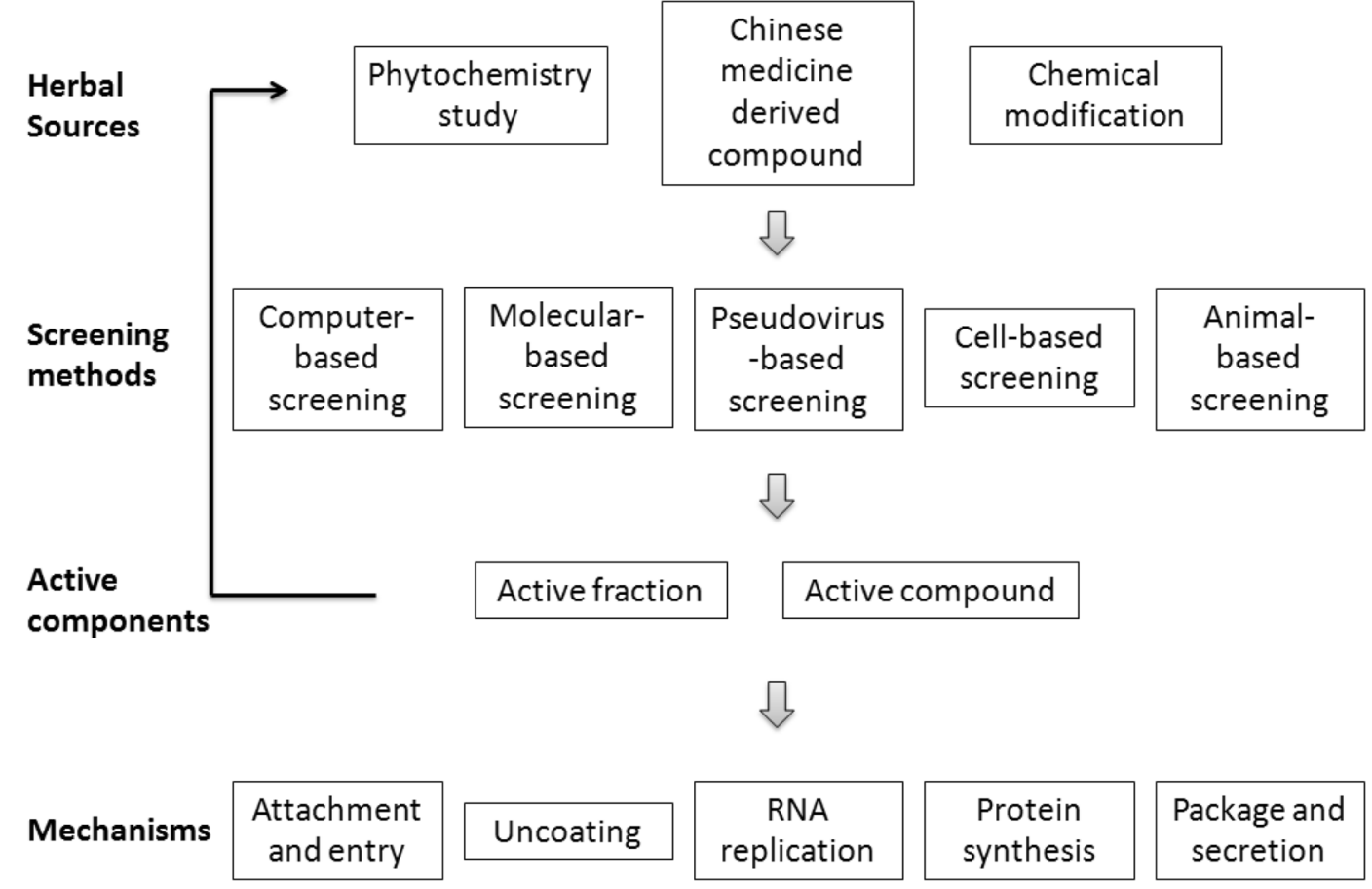

Fig. 2 Schematic diagram of the strategies used to assess anti-EV71 activities of Chinese herbal medicines. Shown are different methods that are used to screen for anti-EV71 activity in fractions and compounds from Chinese herbal medicines. The anti-EV71 mechanisms target different points in the EV71 life cycle

uses two types of reporter viruses, specifically a pseudovirus with luciferase-encoding RNA replicons encapsulated by viral capsid proteins and a full-length reporter virus expressing enhanced green fluorescent protein. The two reporters can be used to screen for possible hits and then to conduct a cell-based assay to confirm the activity [80].

Current research on anti-EV71 drug development is mostly carried out in vitro with a few in vivo studies. The current evidence for the clinical application of $\mathrm{CM}$ in HFMD treatment is still insufficient to determine the efficacy, due to the numerous factors, such as the quality control of CM $[164,165]$, and sufficient sample sizes, improved randomization, and better group organization in clinical studies.

\section{Conclusion}

This review summarized the group of anti-EV71 molecules that have been isolated from CHM and have been applied clinically for this purpose.

\footnotetext{
Abbreviations

EV71: enterovirus 71; HFMD: hand, foot and mouth disease; IFNs: interferons; CPE: cytopathic effect; HRV: human rhinovirus; CHM: Chinese herbal medicine; CM: Chinese medicine; SI: selective index; HBV: Hepatitis B virus; CVB3: Coxsackievirus B3; HSV: Herpes simplex virus; CVA16: Coxsackievirus A16; IL: interleukin; KGS: Kalanchoe gracilis; EA: acetate; BuOH: $n$-butanol; SMGGT: ShengMa-Ge-Gen-Tang; RSV: respiratory syncytial virus; GQP: GuiQi polysaccharides;
}

IRES: internal ribosome entry site; PI4KB: phosphatidylinositol 4-kinase III $\beta$; OSBP: Oxysterol-binding protein; CR: chrysin; CPI: chrysin phosphate ester; ROS: reactive oxygen species; EGCG: Epigallocatechin gallate; GCG: Gallocatechin gallate; GLTA: Lanosta-7,9(11),24-trien-3-one,15; 26-dihydroxy; GLTB: Ganoderic acid Y; MLB: Magnesium lithospermate B; RA: Rosmarinic acid; HIV: human immunodeficiency virus.

\section{Authors' contributions}

HXX conducted this review. MJW and LT performed the literature search and selection, and wrote the manuscript. All authors read and approved the final manuscript.

\section{Author details}

1 School of Pharmacy, Shanghai University of Traditional Chinese Medicine, Shanghai 201203, China. ${ }^{2}$ Engineering Research Center of Shanghai Colleges for TCM New Drug Discovery, Shanghai 201203, China. ${ }^{3}$ Xinxiang Medical University, Jinsui Road 601, Xinxiang, Henan 453003, China.

\section{Acknowledgements}

This paper was supported by the National Major Scientific and Technological Special Project for "Significant New Drug Development" during the Twelfth Five-year Plan Period (No. 2013ZX09103002-020), the Program of Shanghai University of Traditional Chinese Medicine (No. 2012JW06), the National Natural Science Foundation of China (No. 81303289). The authors thank Dr. Yuanzhi Lao (Shanghai University of Traditional Chinese Medicine) and Dr. Donovanst Claire Green (London Metropolitan University) for their advice and careful reading of the preliminary version of this paper.

\section{Competing interests}

All authors declare that they have no competing interests.

Received: 1 December 2014 Accepted: 8 January 2016 Published online: 28 January 2016 


\section{References}

1. Brown BA, Pallansch MA. Complete nucleotide sequence of enterovirus 71 is distinct from poliovirus. Virus Res. 1995;39(2-3):195-205.

2. Chang LY, Lin TY, Hsu KH, Huang YC, Lin KL, Hsueh C, et al. Clinical features and risk factors of pulmonary oedema after enterovirus-71-related hand, foot, and mouth disease. Lancet. 1999;354(9191):1682-6. doi:10.1016/s0140-6736(99)04434-7.

3. McMinn PC. An overview of the evolution of enterovirus 71 and its clinical and public health significance. FEMS Microbiol Rev. 2002;26(1):91-107.

4. AbuBakar S, Sam IC, Yusof J, Lim MK, Misbah S, MatRahim N, et al. Enterovirus 71 outbreak, Brunei. Emerg Infect Dis. 2009;15(1):79-82. doi:10.3201/eid1501.080264

5. Chumakov M, Voroshilova M, Shindarov L, Lavrova I, Gracheva L, Koroleva G, et al. Enterovirus 71 isolated from cases of epidemic poliomyelitis-like disease in Bulgaria. Arch Virol. 1979;60(3-4):329-40.

6. Schmidt $\mathrm{NJ}$, Lennette $\mathrm{EH}, \mathrm{Ho} H \mathrm{H}$. An apparently new enterovirus isolated from patients with disease of the central nervous system. J Infect Dis. 1974;129(3):304-9.

7. Shimizu H, Utama A, Yoshii K, Yoshida H, Yoneyama T, Sinniah M, et al. Enterovirus 71 from fatal and nonfatal cases of hand, foot and mouth disease epidemics in Malaysia, Japan and Taiwan in 1997-1998. Jpn J Infect Dis. 1999;52(1):12-5.

8. Bryson YJ. Promising new antiviral drugs. J Am Acad Dermatol. 1988;18(1 Pt 2):212-8

9. Lu J, Yi L, Zhao J, Yu J, Chen Y, Lin MC, et al. Enterovirus 71 disrupts interferon signaling by reducing the level of interferon receptor 1. J Virol. 2012;86(7):3767-76. doi:10.1128/jvi.06687-11.

10. Hermans PE, Cockerill FR 3rd. Antiviral agents. Mayo Clin Proc. 1983;58(4):217-22.

11. Huggins JW. Prospects for treatment of viral hemorrhagic fevers with ribavirin, a broad-spectrum antiviral drug. Rev Infect Dis. 1989;11(Suppl 4):S750-61.

12. Kaiser L, Crump CE, Hayden FG. In vitro activity of pleconaril and AG7088 against selected serotypes and clinical isolates of human rhinoviruses. Antiviral Res. 2000;47(3):215-20.

13. Zhang Y, Simpson AA, Ledford RM, Bator CM, Chakravarty S, Skochko $G A$, et al. Structural and virological studies of the stages of virus replication that are affected by antirhinovirus compounds. J Virol. 2004;78(20):11061-9. doi:10.1128/jvi.78.20.11061-11069.2004.

14. Wang J, Fan T, Yao X, Wu Z, Guo L, Lei X, et al. Crystal structures of enterovirus $713 \mathrm{C}$ protease complexed with rupintrivir reveal the roles of catalytically important residues. J Virol. 2011;85(19):10021-30. doi:10.1128/jvi.05107-11.

15. Li T, Peng T. Traditional Chinese herbal medicine as a source of molecules with antiviral activity. Antiviral Res. 2013;97(1):1-9. doi:10.1016/j. antiviral.2012.10.006

16. Zhang GL, Li ZG, Dong LL, Tong JB. Shou Zu Kou Bing Zhong Yi Bing Yin Bing Ji De Ren Shi Gai Kuang. Clin J Tradit Chin Med. 2010;7:567-70.

17. Yin D, Li J, Lei X, Liu Y, Yang Z, Chen K. Antiviral activity of total flavonoid extracts from Selaginella moellendorffii Hieron against coxsackie virus B3 in vitro and in vivo. Evid Based Complement Alternat Med. 2014:2014:950817. doi:10.1155/2014/950817.

18. Zandi K, Lim TH, Rahim NA, Shu MH, Teoh BT, Sam SS, et al. Extract of Scutellaria baicalensis inhibits dengue virus replication. BMC Complement Altern Med. 2013;13:91. doi:10.1186/1472-6882-13-91.

19. Tseng YP, Wu YC, Leu YL, Yeh SF, Chou CK. Scutellariae radix suppresses hepatitis B virus production in human hepatoma cells. Front Biosci (Elite Ed). 2010;2:1538-47

20. Xiuying $P$, Jianping L, Ruofeng S, Liye Z, Xuehong W, Yan L. Therapeutic efficacy of Hypericum perforatum L. extract for mice infected with an influenza A virus. Can J Physiol Pharmacol. 2012;90(2):123-30. doi:10.1139/y11-111.

21. Zhang HE. Qing Re Jie Du Yao De Ying Yong He Jin Zhan. Liaoning J Tradit Chin Med. 1981;12:45.

22. Kumar M, Prasad SK, Hemalatha S. A current update on the phytopharmacological aspects of Houttuynia cordata Thunb. Pharmacogn Rev. 2014;8(15):22-35. doi:10.4103/0973-7847.125525.

23. Chen $X$, Wang Z, Yang Z, Wang J, Xu Y, Tan RX, et al. Houttuynia cordata blocks HSV infection through inhibition of NF-kB activation. Antiviral Res. 2011:92(2):341-5. doi:10.1016/j.antiviral.2011.09.005.
24. Li W, Fan T, Zhang Y, Fan T, Zhou P, Niu X, et al. Houttuynia cordata Thunb. volatile oil exhibited anti-inflammatory effects in vivo and inhibited nitric oxide and tumor necrosis factor-a Producaation in LPS-stimulated mouse peritoneal macrophages in vitro. Phytother Res. 2012. doi:10.1002/ptr.4905.

25. Miyata M, Koyama T, Yazawa K. Water extract of Houttuynia cordata Thunb. leaves exerts anti-obesity effects by inhibiting fatty acid and glycerol absorption. J Nutr Sci Vitaminol (Tokyo). 2010;56(2):150-6.

26. Tang YJ, Yang JS, Lin CF, Shyu WC, Tsuzuki M, Lu CC, et al. Houttuynia cordata Thunb extract induces apoptosis through mitochondrialdependent pathway in HT-29 human colon adenocarcinoma cells. Oncol Rep. 2009;22(5):1051-6.

27. Lin TY, Liu YC, Jheng JR, Tsai HP, Jan JT, Wong WR, et al. Anti-enterovirus 71 activity screening of chinese herbs with anti-infection and inflammation activities. Am J Chin Med. 2009;37(1):143-58. doi:10.1142/ s0192415x09006734.

28. Chen X, Wang C, Xu L, Chen X, Wang W, Yang G, et al. A laboratory evaluation of medicinal herbs used in China for the treatment of hand, foot, and mouth disease. Evid Based Complement Alternat Med. 2013:2013:504563. doi:10.1155/2013/504563.

29. Shi SY, Zhao Y, Wu RX. Qi Ye Yi Zhi Hua Ding Zhi Liao Fu She Yao Shang Zhi Zhi Ti Zhong Zhang Yi Bai Li. J Emerg Tradit Chin Med. 2011;10:1661

30. Li FR, Jiao P, Yao ST, Sang H, Qin SC, Zhang W, et al. Paris polyphylla Smith extract induces apoptosis and activates cancer suppressor gene connexin26 expression. Asian Pac J Cancer Prev. 2012;13(1):205-9.

31. Deng D, Lauren DR, Cooney JM, Jensen DJ, Wurms KV, Upritchard JE, et al. Antifungal saponins from Paris polyphylla Smith. Planta Med. 2008;74(11):1397-402. doi:10.1055/s-2008-1081345.

32. Wang YC, Yi TY, Lin KH. In vitro activity of Paris polyphylla Smith against enterovirus 71 and coxsackievirus B3 and its immune modulation. Am J Chin Med. 2011;39(6):1219-34. doi:10.1142/s0192415x11009512.

33. Lai ZR, Ho YL, Huang SC, Huang TH, Lai SC, Tsai JC, et al. Antioxidant, anti-inflammatory and antiproliferative activities of Kalanchoe gracilis (L.) DC stem. Am J Chin Med. 2011;39(6):1275-90. doi:10.1142/ s0192415x1100955x.

34. Lai ZR, Peng WH, Ho YL, Huang SC, Huang TH, Lai SC, et al. Analgesic and anti-inflammatory activities of the methanol extract of Kalanchoe gracilis (L.) DC stem in mice. Am J Chin Med. 2010;38(3):529-46. doi:10.1142/s0192415×10008032.

35. Wu PL, Hsu YL, Wu TS, Bastow KF, Lee KH. Kalanchosides A-C, new cytotoxic bufadienolides from the aerial parts of Kalanchoe gracilis. Org Lett. 2006;8(23):5207-10. doi:10.1021/ol061873m.

36. Wang CY, Huang SC, Zhang Y, Lai ZR, Kung SH, Chang YS, et al. Antiviral ability of Kalanchoe gracilis leaf extract against enterovirus 71 and coxsackievirus A16. Evid Based Complement Alternat Med. 2012;2012:503165. doi:10.1155/2012/503165.

37. Wang CY, Huang SC, Lai ZR, Ho YL, Jou YJ, Kung SH, et al. Eupafolin and ethyl Acetate fraction of Kalanchoe gracilis stem extract show potent antiviral activities against enterovirus 71 and coxsackievirus A16. Evid Based Complement Alternat Med. 2013;2013:591354. doi:10.1155/2013/591354.

38. Choi JY, Lee JM, Lee DG, Cho S, Yoon YH, Cho EJ, et al. The n-Butanol fraction and rutin from Tartary Buckwheat improve cognition and memory in an in vivo model of amyloid- $\beta$-induced Alzheimer's disease. J Med Food. 2015;18(6):631-41. doi:10.1089/jmf.2014.3292.

39. Qian JZ, Zhang YM, Ding LJ. Pao Tong Hua De Huo Xing Cheng Fen Ji Qi Yao Li Zuo Yong Zong Shu. Jiangsu Agric Sci. 2013;5:7-9.

40. Ji P, Chen C, Hu Y, Zhan Z, Pan W, Li R, et al. Antiviral activity of Paulownia tomentosa against enterovirus 71 of hand, foot, and mouth disease. Biol Pharm Bull. 2015;38(1):1-6. doi:10.1248/bpb.b14-00357.

41. Yeo SG, Song JH, Hong EH, Lee BR, Kwon YS, Chang SY, et al. Antiviral effects of Phyllanthus urinaria containing corilagin against human enterovirus 71 and coxsackievirus A16 in vitro. Arch Pharm Res. 2015;38(2):193-202. doi:10.1007/s12272-014-0390-9.

42. Wu WY, Wang YP. Pharmacological actions and therapeutic applications of Salvia miltiorrhiza depside salt and its active components. Acta Pharmacol Sin. 2012;33(9):1119-30. doi:10.1038/aps.2012.126.

43. Wu BW, Pan TL, Leu YL, Chang YK, Tai PJ, Lin KH, et al. Antiviral effects of Salvia miltiorrhiza (Danshen) against enterovirus 71. Am J Chin Med. 2007:35(1):153-68. doi:10.1142/s0192415×07004709. 
44. Wx Q. Fu J. Ge Gen De Yao Li Zuo Yong Yan Jiu Jin Zhan. J Beijing Univ Tradional Chin Med. 1994;3:39-41.

45. Jin SE, Son YK, Min BS, Jung HA, Choi JS. Anti-inflammatory and antioxidant activities of constituents isolated from Pueraria lobata roots. Arch Pharm Res. 2012;35(5):823-37. doi:10.1007/s12272-012-0508-x.

46. Prasain JK, Peng N, Rajbhandari R, Wyss JM. The Chinese Pueraria root extract (Pueraria lobata) ameliorates impaired glucose and lipid metabolism in obese mice. Phytomedicine. 2012;20(1):17-23. doi:10.1016/j. phymed.2012.09.017.

47. Lin TJ, Yeh CF, Wang KC, Chiang LC, Tsai JJ, Chang JS. Water extract of Pueraria lobata Ohwi has anti-viral activity against human respiratory syncytial virus in human respiratory tract cell lines. Kaohsiung J Med Sci. 2013;29(12):651-7. doi:10.1016/j.kjms.2013.06.001.

48. Su FM, Chang JS, Wang KC, Tsai JJ, Chiang LC. A water extract of Pueraria lobata inhibited cytotoxicity of enterovirus 71 in a human foreskin fibroblast cell line. Kaohsiung J Med Sci. 2008;24(10):523-30. doi:10.1016/s1607-551x(09)70011-7.

49. Gao X, Wang W, Wei S, Li W. Review of pharmacological effects of Glycyrrhiza radix and its bioactive compounds. Zhongguo Zhong Yao Za Zhi. 2009;34(21):2695-700.

50. Kuo KK, Chang JS, Wang KC, Chiang LC. Water extract of Glycyrrhiza uralensis inhibited enterovirus 71 in a human foreskin fibroblast cell line. Am J Chin Med. 2009;37(2):383-94. doi:10.1142/s0192415x09006904.

51. Hsu HW, Wang JH, Liu LC, Chen CS, Wang YC. Anti-enterovirus 71 activity screening of Taiwanese folk medicinal plants and immune modulation of Ampelopsis brevipedunculata (Maxim.) Trautv against the virus. Afr J Microbiol Res. 2011;5:2500-11.

52. Pang R, Tao JY, Zhang SL, Chen KL, Zhao L, Yue X, et al. Ethanol extract from Ampelopsis sinica root exerts anti-hepatitis $B$ virus activity via inhibition of p53 pathway in vitro. Evid Based Complement Alternat Med. 2011;2011:939205. doi:10.1093/ecam/neq011.

53. Wu MJ, Yen JH, Wang L, Weng CY. Antioxidant activity of Porcelainberry (Ampelopsis brevipedunculata (Maxim.) Trautv.). Am J Chin Med 2004;32(5):681-93. doi:10.1142/s0192415x04002387.

54. Yabe N, Matsui H. Ampelopsis brevipedunculata (Vitaceae) extract inhibits a progression of carbon tetrachloride-induced hepatic injury in the mice. Phytomedicine. 2000;7(6):493-8. doi:10.1016/ s0944-7113(00)80035-5.

55. Zhou BN. Some progress on the chemistry of natural bioactive terpenoids from Chinese medicinal plants. Mem Inst Oswaldo Cruz. 1991;86(Suppl 2):219-26.

56. Hong JY, Chung HJ, Lee HJ, Park HJ, Lee SK. Growth inhibition of human lung cancer cells via down-regulation of epidermal growth factor receptor signaling by yuanhuadine, a daphnane diterpene from Daphne genkwa. J Nat Prod. 2011;74(10):2102-8. doi:10.1021/np2003512.

57. Lee MY, Park BY, Kwon OK, Yuk JE, Oh SR, Kim HS, et al. Anti-inflammatory activity of (-)-aptosimon isolated from Daphne genkwa in RAW264.7 cells. Int Immunopharmacol. 2009;9(7-8):878-85. doi:10.1016/j.intimp.2009.03.012.

58. Park BY, Min BS, Ahn KS, Kwon OK, Joung H, Bae KH, et al. Daphnane diterpene esters isolated from flower buds of Daphne genkwa induce apoptosis in human myelocytic HL-60 cells and suppress tumor growth in Lewis lung carcinoma (LLC)-inoculated mouse model. J Ethnopharmacol. 2007;111(3):496-503. doi:10.1016/j.jep.2006.12.023.

59. Chang CW, Leu YL, Horng JT. Daphne Genkwa sieb. Et zucc. Watersoluble extracts act on enterovirus 71 by inhibiting viral entry. Viruses. 2012:4(4):539-56. doi:10.3390/v4040539.

60. Wang KC, Chang JS, Chiang LC, Lin CC. Sheng-Ma-Ge-Gen-Tang (Shoma-kakkon-to) inhibited cytopathic effect of human respiratory syncytial virus in cell lines of human respiratory tract. J Ethnopharmacol. 2011;135(2):538-44. doi:10.1016/j.jep.2011.03.058.

61. Chang JS, Wang KC, Chiang LC. Sheng-Ma-Ge-Gen-Tang inhibited enterovirus 71 infection in human foreskin fibroblast cell line. J Ethnopharmacol. 2008;119(1):104-8. doi:10.1016/j.jep.2008.06.004.

62. Pu X, Wang H, Li Y, Fan W, Yu S. Antiviral activity of GuiQi polysaccharides against enterovirus 71 in vitro. Virol Sin. 2013;28(6):352-9. doi:10.1007/s12250-013-3376-8.

63. Chiang LC, Ng LT, Cheng PW, Chiang W, Lin CC. Antiviral activities of extracts and selected pure constituents of Ocimum basilicum. Clin Exp Pharmacol Physiol. 2005;32(10):811-6. doi:10.1111/j.1440-1681.2005.04270.x.
64. Lv X, Qiu M, Chen D, Zheng N, Jin Y, Wu Z. Apigenin inhibits enterovirus 71 replication through suppressing viral IRES activity and modulating cellular JNK pathway. Antiviral Res. 2014;109:30-41. doi:10.1016/j. antiviral.2014.06.004.

65. Zhang W, Qiao H, LvY, Wang J, Chen X, Hou Y, et al. Apigenin inhibits enterovirus-71 infection by disrupting viral RNA association with trans-acting factors. PLoS One. 2014;9(10):e110429. doi:10.1371/journal.pone.0110429.

66. College JNM. A dictionary of traditional Chinese drugs. Shanghai People's press; 1977.

67. Zhu QC, Wang Y, Liu YP, Zhang RQ, Li X, Su WH, et al. Inhibition of enterovirus 71 replication by chrysosplenetin and penduletin. Eur J Pharm Sci. 2011;44(3):392-8. doi:10.1016/j.ejps.2011.08.030.

68. Arita M, Philipov S, Galabov AS. Phosphatidylinositol 4-kinase III beta is the target of oxoglaucine and pachypodol (Ro 09-0179) for their anti-poliovirus activities, and is located at upstream of the target step of brefeldin A. Microbiol Immunol. 2015;59(6):338-47. doi:10.1111/1348-0421.12261.

69. Arita M, Kojima H, Nagano T, Okabe T, Wakita T, Shimizu H. Phosphatidylinositol 4-kinase III beta is a target of enviroxime-like compounds for antipoliovirus activity. J Virol. 2011;85(5):2364-72. doi:10.1128/ jvi.02249-10.

70. Arita M, Kojima H, Nagano T, Okabe T, Wakita T, Shimizu H. Oxysterolbinding protein family I is the target of minor enviroxime-like compounds. J Virol. 2013;87(8):4252-60. doi:10.1128/jvi.03546-12.

71. Hsu NY, Ilnytska O, Belov G, Santiana M, Chen YH, Takvorian PM, et al. Viral reorganization of the secretory pathway generates distinct organelles for RNA replication. Cell. 2010;141(5):799-811. doi:10.1016/j. cell.2010.03.050.

72. Ishikawa-Sasaki K, Sasaki J, Taniguchi K. A complex comprising phosphatidylinositol 4-kinase IIIbeta, ACBD3, and Aichi virus proteins enhances phosphatidylinositol 4-phosphate synthesis and is critical for formation of the viral replication complex. J Virol. 2014;88(12):6586-98. doi:10.1128/jvi.00208-14.

73. Arita M, Wakita T, Shimizu H. Characterization of pharmacologically active compounds that inhibit poliovirus and enterovirus 71 infectivity. J Gen Virol. 2008;89(Pt 10):2518-30. doi:10.1099/vir.0.2008/002915-0.

74. van der Schaar HM, Leyssen P, Thibaut HJ, de Palma A, van der Linden L, Lanke $\mathrm{KH}$, et al. A novel, broad-spectrum inhibitor of enterovirus replication that targets host cell factor phosphatidylinositol 4-kinase IIIbeta. Antimicrob Agents Chemother. 2013;57(10):4971-81. doi:10.1128/ aac.01175-13.

75. Spickler C, Lippens J, Laberge MK, Desmeules S, Bellavance E, Garneau $\mathrm{M}$, et al. Phosphatidylinositol 4-kinase III beta is essential for replication of human rhinovirus and its inhibition causes a lethal phenotype in vivo. Antimicrob Agents Chemother. 2013;57(7):3358-68. doi:10.1128/aac.00303-13.

76. Tsai FJ, Lin CW, Lai CC, Lan YC, Lai CH, Hung CH, et al. Kaempferol inhibits enterovirus 71 replication and internal ribosome entry site (IRES) activity through FUBP and HNRP proteins. Food Chem. 2011;128(2):312-22. doi:10.1016/j.foodchem.2011.03.022.

77. Lirdprapamongkol K, Sakurai H, Abdelhamed S, Yokoyama S, Maruyama T, Athikomkulchai S, et al. A flavonoid chrysin suppresses hypoxic survival and metastatic growth of mouse breast cancer cells. Oncol Rep. 2013;30(5):2357-64. doi:10.3892/or.2013.2667.

78. El-Bassossy HM, Abo-Warda SM, Fahmy A. Chrysin and luteolin attenuate diabetes-induced impairment in endothelial-dependent relaxation: effect on lipid profile, AGEs and NO generation. Phytother Res. 2013;27(11):1678-84. doi:10.1002/ptr.4917.

79. Wang J, Zhang T, Du J, Cui S, Yang F, Jin Q. Anti-enterovirus 71 effects of chrysin and its phosphate ester. PLoS One. 2014;9(3):e89668. doi:10.1371/journal.pone.0089668.

80. Xu L, Su W, Jin J, Chen J, Li X, Zhang X, et al. Identification of luteolin as enterovirus 71 and coxsackievirus A16 inhibitors through reporter viruses and cell viability-based screening. Viruses. 2014;6(7):2778-95. doi:10.3390/v6072778.

81. Zhang X, Liang MH, Huang WJ, Guo YH, Lu HL, Xin M. Mang Bing Hua Huang Su You Dao Pang Guang Ai Xi Bao Diao Wang Zuo Yong. Chin J Public Health. 2015;3:314-7.

82. Wang H, Zhang D, Ge M, Li Z, Jiang J, Li Y. Formononetin inhibits enterovirus 71 replication by regulating COX-2/PGE2 expression. Virol J. 2015;12(1):35. doi:10.1186/s12985-015-0264-X. 
83. Choi HJ, Lim CH, Song JH, Baek SH, Kwon DH. Antiviral activity of raoulic acid from Raoulia australis against Picornaviruses. Phytomedicine. 2009;16(1):35-9. doi:10.1016/j.phymed.2008.10.012.

84. Choi HJ, Song JH, Lim CH, Baek SH, Kwon DH. Anti-human rhinovirus activity of raoulic acid from Raoulia australis. J Med Food. 2010;13(2):326-8. doi:10.1089/jmf.2009.1149.

85. Lin CN, Lu CM, Cheng MK, Gan KH, Won SJ. The cytotoxic principles of Solanum incanum. J Nat Prod. 1990;53(2):513-6.

86. Ming LJ, Yin AC. Therapeutic effects of glycyrrhizic acid. Nat Prod Commun. 2013;8(3):415-8.

87. Wang J, Chen X, Wang W, Zhang Y, Yang Z, Jin Y, et al. Glycyrrhizic acid as the antiviral component of Glycyrrhiza uralensis Fisch. against coxsackievirus A16 and enterovirus 71 of hand foot and mouth disease. J Ethnopharmacol. 2013;147(1):114-21. doi:10.1016/j.jep.2013.02.017.

88. Xie XJ, Zhang JH, Ma AH. Zhong Yao Zhi Zi Yan Jiu Jin Zhan LiShiZhen. Med Mater Med Res. 2000;10:943-5.

89. Lin YJ, Lai CC, Lai CH, Sue SC, Lin CW, Hung CH, et al. Inhibition of enterovirus 71 infections and viral IRES activity by Fructus gardeniae and geniposide. Eur J Med Chem. 2013;62:206-13. doi:10.1016/j. ejmech.2012.12.038.

90. Bishop KS, Kao CH, Xu Y, Glucina MP, Paterson RR, Ferguson LR. From 2000 years of Ganoderma lucidum to recent developments in nutraceuticals. Phytochemistry. 2015;114:56-65. doi:10.1016/j. phytochem.2015.02.015.

91. Zhang W, Tao J, Yang X, Yang Z, Zhang L, Liu H, et al. Antiviral effects of two Ganoderma lucidum triterpenoids against enterovirus 71 infection. Biochem Biophys Res Commun. 2014;449(3):307-12. doi:10.1016/j. bbrc.2014.05.019.

92. Song J, Yeo SG, Hong EH, Lee BR, Kim JW, Kim J, et al. Antiviral activity of hederasaponin B from hedera helix against enterovirus 71 subgenotypes C3 and C4a. Biomol Ther (Seoul). 2014;22(1):41-6. doi:10.4062/ biomolther.2013.108.

93. Kang $\sqcup$, Choi YJ, Lee SG. Stimulation of TRAF6/TAK1 degradation and inhibition of JNK/AP-1 signalling by ginsenoside Rg3 attenuates hepatitis B virus replication. Int J Biochem Cell Biol. 2013;45(11):2612-21. doi:10.1016/j.biocel.2013.08.016.

94. Lee KT, Jung TW, Lee HJ, Kim SG, Shin YS, Whang WK. The antidiabetic effect of ginsenoside Rb2 via activation of AMPK. Arch Pharm Res. 2011;34(7):1201-8. doi:10.1007/s12272-011-0719-6.

95. Song $J H$, Choi HJ, Song HH, Hong EH, Lee BR, Oh SR, et al. Antiviral activity of ginsenosides against coxsackievirus B3, enterovirus 71, and human rhinovirus 3. J Ginseng Res. 2014;38(3):173-9. doi:10.1016/j. jgr.2014.04.003.

96. Ho HY, Cheng ML, Weng SF, Leu YL, Chiu DT. Antiviral effect of epigallocatechin gallate on enterovirus 71. J Agric Food Chem. 2009:57(14):6140-7. doi:10.1021/jf901128u.

97. Lee JC, Tsai CY, Kao JY, Kao MC, Tsai SC, Chang CS, et al. Geraniinmediated apoptosis by cleavage of focal adhesion kinase through up-regulation of Fas ligand expression in human melanoma cells. Mol Nutr Food Res. 2008;52(6):655-63. doi:10.1002/mnfr.200700381.

98. Lin SY, Wang CC, Lu YL, Wu WC, Hou WC. Antioxidant, anti-semicarbazide-sensitive amine oxidase, and anti-hypertensive activities of geraniin isolated from Phyllanthus urinaria. Food Chem Toxicol. 2008;46(7):2485-92. doi:10.1016/j.fct.2008.04.007.

99. Yang Y, Zhang L, Fan X, Qin C, Liu J. Antiviral effect of geraniin on human enterovirus 71 in vitro and in vivo. Bioorg Med Chem Lett. 2012;22(6):2209-11. doi:10.1016/j.bmcl.2012.01.102.

100. Huang YN, Zhao DD, Gao B, Zhong K, Zhu RX, Zhang Y, et al. Anti-hyperglycemic effect of chebulagic acid from the fruits of Terminalia chebula Retz. Int J Mol Sci. 2012;13(5):6320-33. doi:10.3390/ijms13056320.

101. Lin LT, Chen TY, Lin SC, Chung CY, Lin TC, Wang GH, et al. Broadspectrum antiviral activity of chebulagic acid and punicalagin against viruses that use glycosaminoglycans for entry. BMC Microbiol. 2013;13(1):187. doi:10.1186/1471-2180-13-187.

102. Yang Y, Xiu J, Liu J, Zhang L, Li X, Xu Y, et al. Chebulagic acid, a hydrolyzable tannin, exhibited antiviral activity in vitro and in vivo against human enterovirus 71. Int J Mol Sci. 2013;14(5):9618-27. doi:10.3390/ ijms14059618.
103. Yang Y, Xiu J, Zhang L, Qin C, Liu J. Antiviral activity of punicalagin toward human enterovirus 71 in vitro and in vivo. Phytomedicine. 2012;20(1):67-70. doi:10.1016/j.phymed.2012.08.012.

104. Fu WM, Wang WM, Wang H, Zhu $X$, Liang $Y$, Kung HF, et al. 1,3,5-trihydroxy-13,13-dimethyl-2H-pyran [7,6-b] xanthone directly targets heat shock protein 27 in hepatocellular carcinoma. Cell Biol Int. 2014;38(2):272-6. doi:10.1002/cbin.10193.

105. Liu M, Tao L, Chau SL, Wu R, Zhang H, Yang Y, et al. Folding fan mode counter-current chromatography offers fast blind screening for drug discovery. Case study: finding anti-enterovirus 71 agents from Anemarrhena asphodeloides. J Chromatogr A. 2014;1368:116-24. doi:10.1016/j. chroma.2014.09.064

106. Liu M-S, Chau S-L, Ma D-L, Leung C-H, Bian Z-X, Lu A-P, et al. Using two-phase solvent systems for sample pretreatment increases yield of counter-current chromatography: Anemarrhena asphodeloides saponins, a case study. Sep Purif Technol. 2014;138:138-43. doi:10.1016/j. seppur.2014.10.011.

107. Chandan BK, Saxena AK, Shukla S, Sharma N, Gupta DK, Singh K, et al. Hepatoprotective activity of Woodfordia fruticosa Kurz flowers against carbon tetrachloride induced hepatotoxicity. J Ethnopharmacol. 2008;119(2):218-24. doi:10.1016/j.jep.2008.06.020.

108. Dabur R, Gupta A, Mandal TK, Singh DD, Bajpai V, Gurav AM, et al. Antimicrobial activity of some Indian medicinal plants. Afr J Tradit Complement Altern Med. 2007;4(3):313-8.

109. Shah AS, Juvekar AR. In vitro and in vivo immunostimulatory activity of Woodfordia fruticosa flowers on non-specific immunity. Pharm Biol. 2010;48(9):1066-72. doi:10.3109/13880200903490497.

110. Borges A, Ferreira C, Saavedra MJ, Simoes M. Antibacterial activity and mode of action of ferulic and gallic acids against pathogenic bacteria. Microb Drug Resist. 2013;19(4):256-65. doi:10.1089/mdr.2012.0244.

111. Liu KY, Hu S, Chan BC, Wat EC, Lau CB, Hon KL, et al. Anti-inflammatory and anti-allergic activities of Pentaherb formula, Moutan Cortex (Danpi) and gallic acid. Molecules. 2013;18(3):2483-500. doi:10.3390/ molecules18032483.

112. Mansouri MT, Farbood Y, Sameri MJ, Sarkaki A, Naghizadeh B, Rafeirad M. Neuroprotective effects of oral gallic acid against oxidative stress induced by 6-hydroxydopamine in rats. Food Chem. 2013;138(23):1028-33. doi:10.1016/j.foodchem.2012.11.022.

113. Choi HJ, Song JH, Park KS, Baek SH. In vitro anti-enterovirus 71 activity of gallic acid from Woodfordia fruticosa flowers. Lett Appl Microbiol. 2010;50(4):438-40. doi:10.1111/j.1472-765X.2010.02805.x.

114. Yang T, Wang L, Zhu M, Zhang L, Yan L. Properties and molecular mechanisms of resveratrol: a review. Pharmazie. 2015;70(8):501-6.

115. Cottart $\mathrm{CH}$, Nivet-Antoine $\mathrm{V}$, Beaudeux JL. Review of recent data on the metabolism, biological effects, and toxicity of resveratrol in humans. Mol Nutr Food Res. 2013; doi:10.1002/mnfr.201200589.

116. Gao LL, Chen Q, Li JD, Zhu WC, Guo J, Yu SY. Inhibitory effect of resveratrol against enterovirus type 71 in vitro. Nan Fang Yi Ke Da Xue Xue Bao. 2011;31(4):665-8.

117. Zhang L, Li Y, Gu Z, Wang Y, Shi M, Ji Y, et al. Resveratrol inhibits enterovirus 71 replication and pro-inflammatory cytokine secretion in rhabdosarcoma cells through blocking IKKs/NF-kappaB signaling pathway. PLoS One. 2015;10(2):e0116879. doi:10.1371/journal. pone.0116879.

118. Ge B, Qin S, Han L, Lin F, Ren Y. Antioxidant properties of recombinant allophycocyanin expressed in Escherichia coli. J Photochem Photobiol B. 2006:84(3):175-80. doi:10.1016/j.jphotobiol.2006.02.008.

119. Shanab SM, Mostafa SS, Shalaby EA, Mahmoud Gl. Aqueous extracts of microalgae exhibit antioxidant and anticancer activities. Asian Pac J Trop Biomed. 2012;2(8):608-15. doi:10.1016/s2221-1691(12)60106-3.

120. Shih SR, Tsai KN, Li YS, Chueh CC, Chan EC. Inhibition of enterovirus 71-induced apoptosis by allophycocyanin isolated from a blue-green alga Spirulina platensis. J Med Virol. 2003;70(1):119-25. doi:10.1002/ jmv.10363.

121. Arosio B, Gagliano N, Fusaro LM, Parmeggiani L, Tagliabue J, Galetti $P$, et al. Aloe-Emodin quinone pretreatment reduces acute liver injury induced by carbon tetrachloride. Pharmacol Toxicol. 2000;87(5):229-33. 
122. Cardenas C, Quesada AR, Medina MA. Evaluation of the anti-angiogenic effect of aloe-emodin. Cell Mol Life Sci. 2006;63(24):3083-9. doi:10.1007/s00018-006-6399-6.

123. Wasserman L, Avigad S, Beery E, Nordenberg J, Fenig E. The effect of aloe emodin on the proliferation of a new merkel carcinoma cell line. Am J Dermatopathol. 2002;24(1):17-22.

124. Lin CW, Wu CF, Hsiao NW, Chang CY, Li SW, Wan L, et al. Aloe-emodin is an interferon-inducing agent with antiviral activity against Japanese encephalitis virus and enterovirus 71. Int J Antimicrob Agents. 2008;32(4):355-9. doi:10.1016/j.ijantimicag.2008.04.018.

125. Goncagul G, Ayaz E. Antimicrobial effect of garlic (Allium sativum). Recent Pat Antiinfect Drug Discov. 2010;5(1):91-3.

126. Tsubura A, Lai YC, Kuwata M, Uehara N, Yoshizawa K. Anticancer effects of garlic and garlic-derived compounds for breast cancer control. Anticancer Agents Med Chem. 2011;11(3):249-53.

127. Li JH, Yang P, Li AL, Wang Y, Shi ZX, Ke YN, et al. The preventive effect of garlicin on a porcine model of myocardial infarction reperfusion noreflow. Chin J Integr Med. 2012. doi:10.1007/s11655-012-1091-1.

128. Zhang H, Tao L, Fu WW, Liang S, Yang YF, Yuan QH, et al. Prenylated benzoylphloroglucinols and xanthones from the leaves of Garcinia oblongifolia with antienteroviral activity. J Nat Prod. 2014;77(4):1037-46. doi:10.1021/np500124e.

129. Iwata S, Saito S, Kon-ya K, Shizuri Y, Ohizumi Y. Novel marine-derived halogen-containing gramine analogues induce vasorelaxation in isolated rat aorta. Eur J Pharmacol. 2001;432(1):63-70.

130. Wei Y, Shi L, Wang K, Liu M, Yang Q, Yang Z, et al. Discovery of gramine derivatives that inhibit the early stage of EV71 replication in vitro. Molecules. 2014;19(7):8949-64. doi:10.3390/molecules19078949.

131. Li X, Liu Y, Hou X, Peng H, Zhang L, Jiang Q, et al. Chlorogenic acid inhibits the replication and viability of enterovirus 71 in vitro. PLOS One. 2013;8(9):e76007. doi:10.1371/journal.pone.0076007.

132. Chung YC, Hsieh FC, Lin YJ, Wu TY, Lin CW, Lin CT, et al. Magnesium lithospermate $B$ and rosmarinic acid, two compounds present in Salvia miltiorrhiza, have potent antiviral activity against enterovirus 71 infections. Eur J Pharmacol. 2015;755:127-33. doi:10.1016/j. ejphar.2015.02.046.

133. Ma L, Zhu Z, Sun X, Jiang L, Bai Y, Lu X, et al. Growth inhibition effect of matrine on K562 cells mediated by IL-6/JAK/STAT3 signaling pathway. Zhonghua Xue Ye Xue Za Zhi. 2015;36(5):422-6. doi:10.3760/cma.j.i ssn.0253-2727.2015.05.015.

134. Zeng XY, Wang H, Bai F, Zhou X, Li SP, Ren LP, et al. Identification of matrine as a promising novel drug for hepatic steatosis and glucose intolerance with HSP72 as an upstream target. Br J Pharmacol. 2015; doi:10.1111/bph.13209.

135. Liu ZW, Wang JK, Qiu C, Guan GC, Liu XH, Li SJ, et al. Matrine pretreatment improves cardiac function in rats with diabetic cardiomyopathy via suppressing ROS/TLR-4 signaling pathway. Acta Pharmacol Sin. 2015;36(3):323-33. doi:10.1038/aps.2014.127.

136. Xie SB, He XX, Yao SK. Matrine-induced autophagy regulated by p53 through AMP-activated protein kinase in human hepatoma cells. Int J Oncol. 2015. doi:10.3892/ijo.2015.3023.

137. Yang Y, Xiu J, Zhang X, Zhang L, Yan K, Qin C, et al. Antiviral effect of matrine against human enterovirus 71. Molecules. 2012;17(9):10370-6. doi:10.3390/molecules170910370.

138. Szlavik L, Gyuris A, Minarovits J, Forgo P, Molnar J, Hohmann J. Alkaloids from Leucojum vernum and antiretroviral activity of Amaryllidaceae alkaloids. Planta Med. 2004;70(9):871-3. doi:10.1055/s-2004-827239.

139. Wang P, Li LF, Wang QY, Shang LQ, Shi PY, Yin Z. Anti-dengue-virus activity and structure-activity relationship studies of lycorine derivatives. ChemMedChem. 2014;9(7):1522-33. doi:10.1002/ cmdc.201300505.

140. Li L, Dai HJ, Ye M, Wang SL, Xiao XJ, Zheng J, et al. Lycorine induces cell-cycle arrest in the G0/G1 phase in $\mathrm{K} 562$ cells via HDAC inhibition. Cancer Cell Int. 2012;12(1):49. doi:10.1186/1475-2867-12-49.

141. Hu M, Peng S, He Y, Qin M, Cong X, Xing Y, et al. Lycorine is a novel inhibitor of the growth and metastasis of hormone-refractory prostate cancer. Oncotarget. 2015;6:15348.

142. Chen D, Cai J, Yin J, Jiang J, Jing C, Zhu Y, et al. Lycorine-derived phenanthridine downregulators of host $\mathrm{Hsc} 70$ as potential hepatitis C virus inhibitors. Future Med Chem. 2015;7(5):561-70. doi:10.4155/ fmc.15.14.
143. leven M, van den Berghe DA, Vlietinck AJ. Plant antiviral agents. IV. Influence of lycorine on growth pattern of three animal viruses. Planta Med. 1983;49(2):109-14.

144. Mikami M, Kitahara M, Kitano M, Ariki Y, Mimaki Y, Sashida Y, et al. Suppressive activity of lycoricidinol (narciclasine) against cytotoxicity of neutrophil-derived calprotectin, and its suppressive effect on rat adjuvant arthritis model. Biol Pharm Bull. 1999;22(7):674-8.

145. Liu J, Yang Y, Xu Y, Ma C, Qin C, Zhang L. Lycorine reduces mortality of human enterovirus 71 -infected mice by inhibiting virus replication. Virol J. 2011;8:483. doi:10.1186/1743-422x-8-483

146. Chan KP, Goh KT, Chong CY, Teo ES, Lau G, Ling AE. Epidemic hand, foot and mouth disease caused by human enterovirus 71, Singapore. Emerg Infect Dis. 2003;9(1):78-85. doi:10.3201/eid0901.020112.

147. Fujimoto T, Chikahira M, Yoshida S, Ebira H, Hasegawa A, Totsuka A, et al. Outbreak of central nervous system disease associated with hand, foot, and mouth disease in Japan during the summer of 2000: detection and molecular epidemiology of enterovirus 71. Microbiol Immunol. 2002;46(9):621-7.

148. Ho M, Chen ER, Hsu KH, Twu SJ, Chen KT, Tsai SF, et al. An epidemic of enterovirus 71 infection in Taiwan. Taiwan enterovirus epidemic working group. N Engl J Med. 1999;341(13):929-35. doi:10.1056/ nejm199909233411301.

149. Xing W, Liao Q, Viboud C, Zhang J, Sun J, Wu JT, et al. Hand, foot, and mouth disease in China, 2008-12: an epidemiological study. Lancet Infect Dis. 2014;14(4):308-18. doi:10.1016/s1473-3099(13)70342-6.

150. Huang CC, Liu CC, Chang YC, Chen CY, Wang ST, Yeh TF. Neurologic complications in children with enterovirus 71 infection. N Engl J Med. 1999;341(13):936-42. doi:10.1056/nejm199909233411302.

151. China TMoHo. Diagnosis and treatment guidelines of HFMD 2010. http://www.nhfpc.gov.cn/yzygj/s3593g/201306/6d935c0f43cd4a1fb46 f8f71acf8e245.shtml.

152. Yan YY, Shi GX, Shao J, Wang TM, Wang CZ. Advance in studies on anti-infection of andrographolide and its derivatives in past 10 years. Zhongguo Zhong Yao Za Zhi. 2013;38(22):3819-24.

153. Cao H, Liu Z, Steinmann P, Mu Y, Luo H, Liu J. Chinese herbal medicines for treatment of hand, foot and mouth disease: a systematic review of randomized clinical trials. Eur J Integr Med. 2012;4(1):e85-111. doi:10.1016/j.eujim.2011.11.004.

154. Li X, Zhang C, Shi Q, Yang T, Zhu Q, Tian Y, et al. Improving the efficacy of conventional therapy by adding andrographolide sulfonate in the treatment of severe hand, foot, and mouth disease: a randomized controlled trial. Evid Based Complement Alternat Med. 2013;2013:316250. doi:10.1155/2013/316250.

155. Wen T, Xu W, Liang L, Li J, Ding X, Chen X, et al. Clinical efficacy of andrographolide sulfonate in the treatment of severe hand, foot, and mouth disease (HFMD) is dependent upon inhibition of neutrophil activation. Phytother Res. 2015. doi:10.1002/ptr.5361.

156. Shi GX, Yan YY, Shao J, Zhang MX, Lu KQ, Wang TM, et al. Effect of andrographolide derivative Yanhuning on in vivo Candida albicans biofilms in rats. Zhongguo Zhong Yao Za Zhi. 2014;39(15):2924-9.

157. Xiaomeng Z, Jiarui W, Bing Z, Ling D. Potassium dehydroandrographolide succinate injection for treat- ment of infantile pneumonia: a systematic review and Meta-analysis. J Tradit Chin Med. 2015;35(2):125-33.

158. Wu JR, Zhang XM, Zhang B. Potassium dehydroandrographolide succinate injection for the treatment of child epidemic parotitis: a systematic review and meta-analysis. Chin J Integr Med. 2014. doi:10.1007/ s11655-014-1895-2.

159. Tang LP, Xiao W, Li YF, Li HB, Wang ZZ, Yao XS, et al. Anti-inflammatory effects of reduning injection on lipopolysaccharide-induced acute lung injury of rats. Chin J Integr Med. 2014;20(8):591-9. doi:10.1007/ s11655-014-1758-X.

160. Zuo L, Chen Y, Zhang W. Reduning injection inhibits replication and proliferation of mouse cytomegalovirus and down-regulates the expressions of IFN- $\gamma$ and IL-6 in mouse cytomegalovirus pneumonia. Xi Bao Yu Fen Zi Mian Yi Xue Za Zhi. 2013;29(12):1242-4.

161. Li X, Zhang X, Ding J, Xu Y, Wei D, Tian Y, et al. Comparison between Chinese herbal medicines and conventional therapy in the treatment of severe hand, foot, and mouth disease: a randomized controlled trial. Evid Based Complement Alternat Med. 2014;2014:140764. doi:10.1155/2014/140764. 
162. Ahmadi A, Zorofchian Moghadamtousi S, Abubakar S, Zandi K. Antiviral potential of Algae Polysaccharides isolated from marine sources: a review. Biomed Res Int. 2015;2015:825203. doi:10.1155/2015/825203.

163. Chiu YH, Chan YL, Tsai LW, Li TL, Wu CJ. Prevention of human enterovirus 71 infection by kappa carrageenan. Antiviral Res. 2012;95(2):128-34. doi:10.1016/j.antiviral.2012.05.009.

164. Chang YX, Liu J, Bai Y, Li J, Liu EW, He J, et al. The activity-integrated method for quality assessment of reduning injection by on-line DPPH-CE-DAD. PLoS One. 2014;9(9):e106254. doi:10.1371/journal. pone.0106254.
165. Li H, Yu Y, Wang Z, Geng J, Dai Y, Xiao W, et al. Chemical profiling of Re-Du-Ning injection by ultra-performance liquid chromatography coupled with electrospray ionization tandem quadrupole time-offlight mass spectrometry through the screening of diagnostic ions in MSE mode. PLoS One. 2015;10(4):e0121031. doi:10.1371/journal. pone. 0121031
Submit your next manuscript to BioMed Central and we will help you at every step:

- We accept pre-submission inquiries

- Our selector tool helps you to find the most relevant journal

- We provide round the clock customer support

- Convenient online submission

- Thorough peer review

- Inclusion in PubMed and all major indexing services

- Maximum visibility for your research

Submit your manuscript at www.biomedcentral.com/submit
(OioMed Central 